\title{
TRANSGLUTAMINASE 2 AT THE CROSSROADS BETWEEN CELL DEATH AND SURVIVAL
}

\author{
MAURO PIACENTINI \\ MANUELA D'ELETTO \\ LAURA FALASCA \\ MARIA GRAZIA FARRACE \\ CARLO RODOLFO
}

C O N T E N T S

I. Transglutaminases
A. TYPE 2 Transglutaminase
B. TG2 Functions in the Cell

II. Cell Death

A. TG2 As a Proapoptotic Factor

B. TG2 As an Antiapoptotic Factor

III. Autophagy

IV. TG2 In Diseases

A. Inflammatory Diseases

B. Intracellular Protein Inclusions-Related Disorders

1. Neurodegenerative Diseases

2. Liver Steatohepatitis

3. Cardiac Diseases

V. Conclusions

Acknowledgments

References

\section{TRANSGLUTAMINASES}

Transglutaminases (TGases) are a peculiar family of enzymes that catalyse the post-translational modification of proteins either through protein

Advances in Enzymology and Related Areas of Molecular Biology, Volume 78. Edited by Eric J. Toone.

(C) 2011 John Wiley \& Sons, Inc. Published 2011 by John Wiley \& Sons, Inc. 
cross-linking, via $\varepsilon$ - $(\gamma$-glutamyl) lysine bonds, or through the incorporation of primary amines, at the level peptide-bound glutamine residues [1].

The cross-linked protein products become resistant to mechanical challenge and proteolytic degradation, their accumulation being found in a number of tissues, including skin and hair, in blood clotting, and wound healing [2].

In mammals, nine distinct TGases have been identified at the genomic level [3]; however, to date, only six have been characterized at the protein level. These isoforms are the products of different genes that display a wide structural homology and are members of the papain-like superfamily of cysteine proteases [4]. The characterized enzymes include (1) the plasmatic factor XIII, which is converted by thrombin-dependent proteolysis into the active TGase enzyme, the factor XIIIA, which is involved in the stabilization of fibrin clots and wound healing [5]; (2) the keratinocyte or type 1 transglutaminase (TG1), which exists in both membrane-bound and soluble form, requires proteolysis in order to be activated, and is also involved in the terminal differentiation of keratinocytes [6, 7]; (3) the ubiquitous "tissue" or type 2 transglutaminase (TG2) [8,9]; (4) the epidermal/ hair follicle or type 3 transglutaminase (TG3), which, like TG1, requires proteolysis and is involved in the terminal differentiation of keratinocytes [10]; (5) the prostatic secretory or type 4 transglutaminase (TG4), which is responsible for the formation of the copulatory plug and is essential for fertility in rodents [11]; and (6) the type 5 transglutaminase (TG5), which is involved in keratinocyte differentiation [12]. In tissues, the specific expression of the various isoenzymes is tightly regulated at the transcriptional level $[13,14]$.

All members of the family, with the exception of the nonenzymic erythrocyte band 4.2 protein, possess a catalytic triad of Cys-His-Asp or Cys-HisAsn. The first 3-D structural study on TGases, performed on the zymogenic A subunit of plasma factor XIII, revealed that each factor XIIIA subunit is composed of four domains: (1) $N$-terminal $\beta$-sandwich; (2) core domain, containing the catalytic triad; (3) $C$-terminal $\beta$-barrel 1 and (4) $C$-terminal $\beta$-barrel 2 (see Figure 1). These four domains' organization is highly conserved among all the TGase isoforms.

In addition to the well-characterized cross-linking enzymatic action, some members of the TGase family participate in a vast array of biological processes through actions not involving their transamidase catalytic activity [9]. In fact, TG2 [15, 16], TG4 [17], and TG5 [18] are able to bind and to 


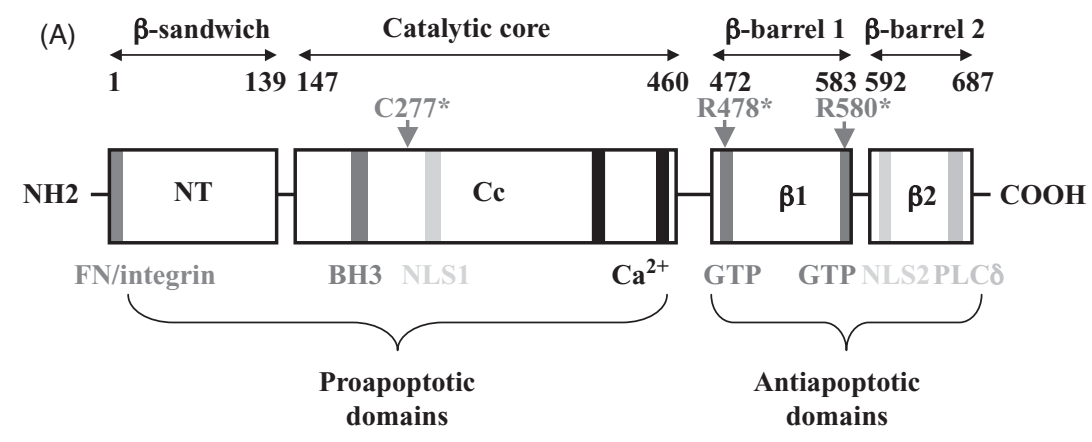

(B)

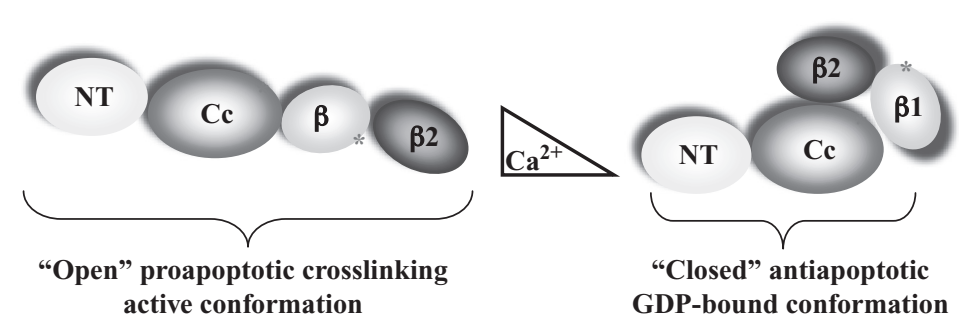

FIGURE 1. TG2 structure and domains. (A) Graphic representation of the four domains of TG2. The following regions are highlighted: FN/integrin binding motif; BH3 domain; C277, active site's cysteine; NLS1 and 2, nuclear localization signals; $\mathrm{Ca}^{2+}$ binding motif; GTP binding motif and relative binding impairing mutations (R478/580); and PLC $\delta$ binding motif. (B) It has been proposed that $\mathrm{Ca}^{2+}$ concentration may control the shift between the "open" proapoptotic (high $\left[\mathrm{Ca}^{2+}\right]$ ) and the "closed" antiapoptotic (low $\left[\mathrm{Ca}^{2+}\right]$ ) conformations of TG2. (See insert for color representation.)

hydrolyze GTP. The GTP binding causes a transition to a compact inactive conformation of the enzyme, leading to the inhibition of its transamidating activity (Figure 1) [19]. However, to date, only TG2 has been shown to utilize this function as a high-molecular-weight $G$ protein $\left(G_{h}\right)$ involved in signaling generated by certain $G$ protein-coupled receptors [20]. TG2 has also been reported to act both as a serine/threonine kinase [21-23] and as a protein disulfide isomerase (PDI) [24, 25]. Finally, FXIIIA [26] and TG2 [27] also act as extra-cellular adaptor proteins to facilitate cell adhesion to the matrix.

Deregulation of these enzymes is associated with a number of human diseases, including autoimmune diseases, cancer, infectious diseases, 
neurodegeneration, progressive tissue fibrosis, and diseases related to the assembly of the stratum corneum of the epidermis of the skin [28].

\section{A. TYPE 2 TRANSGLUTAMINASE}

Tissue or type 2 transglutaminase (TG2) is the most ubiquitous member of the TGase family. The human gene is localized in the chromosome 20q12 and the mouse ortholog in the chromosome $2[29,30]$. The human TG2 gene has been shown to be $32.5 \mathrm{~kb}$ in size and contains 13 exons and 12 introns [ 31 , 32]. The full length TG2 protein consists of 687 amino acids, with a predicted molecular mass of about $78 \mathrm{kDa}$. This protein is present in all organs, due to its constitutive expression in endothelial cells, smooth muscle cells, and fibroblasts as well as in a number of organ-specific cell types [33, 34].

The structure of TG2 was resolved in a crystal complex with GDP [19]; similar to the other TGases, it showed the presence of four distinct domains (Figure 1): (1) an $N$-terminal $\beta$-sandwich, bearing fibronectin and integrin binding sites; (2) a catalytic core, bearing the catalytic triad for the acyltransfer reaction and a $\mathrm{BH} 3$-like domain; and finally, the two $C$-terminal $\beta$-barrel domains-(3) $C$-terminal $\beta$-barrel 1, and (4) $C$-terminal $\beta$-barrel 2. A unique guanidine nucleotide-binding site, which has not been found in any TGase proteins, is located in a cleft between the catalytic core and the first $\beta$-barrel. The sequence coding for this domain is located in the exon 10 of the TG2 gene and shows very poor sequence homology with the same exon in the other TGases. The binding of GTP, but not that of $\mathrm{Ca}^{2+}$, proves to be important for the stability of the enzyme's conformation, suggesting the molecular mechanism by which GTP inhibits TG2 activity. Accordingly, the GTP-TG2 adopts a conformation that decreases the accessibility of the protein matrix to the solvent, thus rendering the accessibility of the active site more difficult [35].

The 3-D organization of the $\mathrm{Cys}^{277}$, $\mathrm{His}^{335}$, and $\mathrm{Asp}^{358}$ in the catalytic triad is similar to that of thiol proteases, such as papain $[36,37]$, and confers high reactivity to $\mathrm{Cys}^{277}$, which might form thioesters with peptidylglutamine moieties of the protein substrates. This high reactivity of Cys ${ }^{277}$ has been employed to develop a wide range of active-site-directed irreversible inhibitors of the enzyme. In the absence of $\mathrm{Ca}^{2+}$, TG2 assumes the basic latent conformation and the reactivity of $\mathrm{Cys}^{277}$ is decreased either by hydrogen bonding, with the phenolic hydroxy group of $\mathrm{Tyr}^{516}$, or by formation of a disulphide, with a neighboring cysteine residue, namely Cys ${ }^{336}$ [38]. It is worth noting that, the pro-apoptotic and pro-survival activities of 
TG2 are confined in discrete domains along the primary sequence of the protein, suggesting a modular and independent phylogenetic evolution.

TG2 is located mostly in the cytosol, but is also found associated with the inner face of the plasma membrane $[15,16]$, with nuclear membrane [39], and in the mitochondria [40,41]. In specific settings, the enzyme has been detected in the extracellular matrix (ECM), or at the cell surface, in association with proteins of the ECM $[42,43]$. In particular, under pathological conditions, TG2 plays an important role in ECM stabilization, during wound healing, angiogenesis, fibrosis, and bone remodeling [44]. The enzyme exerts this extracellular stabilizing function by forming complexes with fibronectin and collagen [45], with $\beta 1 / \beta 3 / \beta 5$ integrins [46], with the heparan sulfate chains of the heparan sulfate proteoglycan receptor, with syndecan 4 [47], or with the orphan G protein-coupled cell-adhesion receptor GPR56 [48]. On the other hand, until today, no in vivo evidences of the physiological role for the extracellular TG2 has been reported.

Inside the cell, TG2 is able to carry out three different enzymatic functions in addition to its transamidase activity. These functions are (1) the GTPase activity and its related intracellular $\mathrm{G}$ protein signaling, via coupling to the $\alpha_{1 \beta} / \alpha_{1 \delta}$-adrenergic receptors [20], the TPA thromboxane A2 receptor [49], and the oxytocin receptor [50]; (2) the serine/threonine kinase activity, with insulin-like growth factor binding protein (IGFBP)-3, p53, or histones as substrates [21-23]; (3) the PDI activity [24,25], for which several mitochondrial substrates have been identified [40, 41, 51].

\section{B. TG2 FUNCTIONS IN THE CELL}

The various TG2 subcellular localizations as well as the large number of identified protein substrates clearly imply the involvement of the enzyme in multiple biological functions. In keeping with this assumption, studies carried out in different cellular populations or under physiological vs. pathological settings failed to provide a unique paradigm. In fact, while some cell types (e.g., endothelial and smooth muscle cells) express constitutive high level of TG2 protein $[34,52]$, other cell types showed an induction of the enzyme as a response to the activation of distinct signaling pathways related to the induction of cellular stress, defence, and/or differentiation. In fact, retinoic acid (RA), TGF $\beta, N F-\kappa B$, and AP-responsive elements have been identified in the regulatory region of the TG2 gene [53]. Nevertheless, the regulation of the various activities of the enzyme relies on multiple heterogeneous factors. The role played by TG2 as a G-protein has been 
clearly described $[54,55]$ in the transduction of the signal from the seven transmembrane-helix receptors to phospholipase $\mathrm{C} \delta$-1 (PLC), which becomes activated after binding of GTP to TG2 [56]. Conversely, high $\mathrm{Ca}^{2+}$ levels might induce the release of the bound GTP/GDP molecule, inhibiting signaling and promoting the transamidating activity. The interaction of TG2 with specific molecules (e.g., with sphingosylphosphocholine) might reduce the $\mathrm{Ca}^{2+}$ requirement for the transglutaminase activity [57]. TG2 activity may also be strongly influenced by nitric oxide: up to 15 of the 18 cysteine residues can be nitrosylated and denitrosylated, in a $\mathrm{Ca}^{2+}$-dependent manner, leading to the inhibition and the activation of the enzyme, respectively [58].

The calcium-activated form of TG2 allows the enzyme to interact and modify major components of the cytoskeleton. Accordingly, after RA induction, TG2 can modify RhoA, a member of Rho GTPases widely involved in cytoskeletal modifications $[59,60]$. These changes result in an increase of the binding of RhoA to ROCK-2 protein kinase and in the autophosophorylation of ROCK-2. Such changes lead to phosphorylation of vimentin, which causes stress fibers formation and increased cell adhesion. Moreover, TG2 can interact with beta-tubulin and with microtubule binding proteins, including tau, which can be eventually cross-linked by the enzyme [61, 62].

Cytoskeleton proteins do not represent the only target of TG2 enzymatic activity. An interesting aspect of action exerted by TG2 in the cell relies on its ability to localize at different cell compartments. It has been proposed that, under certain conditions, TG2 might translocate in the nucleus, through its own nuclear localization sequences (NLS) (Figures 1 and 2) and with the help of importin- $\alpha 3$ [63]. Once in the nucleus, TG2 might function either as a G-protein or as a transamidase activated by nuclear $\mathrm{Ca}^{2+}$-signals, in order to cross-link histones, retinoblastoma $(\mathrm{Rb})$, and SP1 proteins [62, 64-66]. These observations support the hypothesis that TG2 might have a direct role in chromatin post-translational modifications and/or gene expression regulation [40,41].

TG2 protein expression and activity has been shown to be induced in cells undergoing apoptosis in vivo $[67,68]$. Under physiological conditions, TG2 overexpression primes cells for suicide, while its inhibition, through several strategies, results in decreased cell death [40,69]. It has been reported that the enzyme might sensitize cells towards apoptosis by interacting with mitochondria and by shifting them to a higher polarized state $[40,41]$. This event triggers an alteration of the redox status that might provoke the activation of the TG2's PDI activity. At the same time, the massive increase of cytosolic $\mathrm{Ca}^{2+}$ concentration, observed during the later stages of apoptosis, 


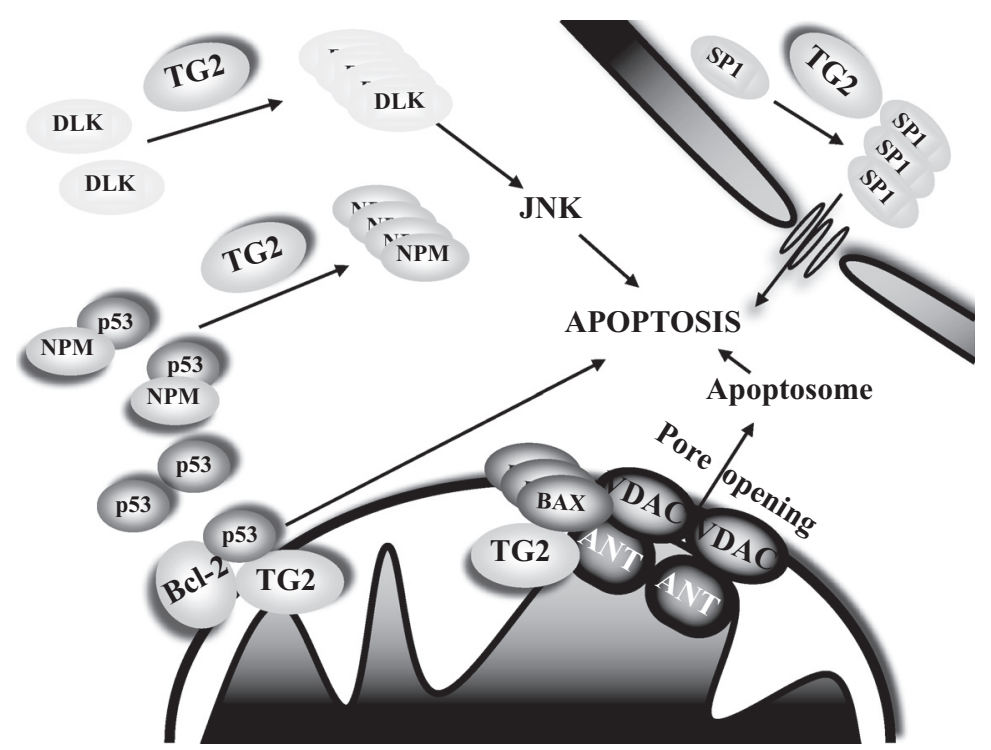

FIGURE 2. TG2 exerts its proapoptotic function by acting on different protein substrates in the cytosol, nucleus, and at mitochondrial level. (See insert for color representation.)

determines the switch of TG2 to its cross-linking configuration in all subcellular compartments. This transition results in an extensive polymerization of intracellular proteins, including actin, $\mathrm{Sp} 1$ and $\mathrm{Rb}$, and the formation of detergent-insoluble structures (Table 1) $[67,69,70]$. This protein scaffold stabilizes the dying cell before its clearance by phagocytosis; thus preventing the release of harmful intracellular components and the activation of an inflammatory or autoimmune response [62]. Under pathological conditions, the death of cells expressing high amounts of TG2 may occur as a result of a "mummification" event caused by an extensive cross-linking of cytosolic proteins without signs of either apoptosis or necrosis [95].

\section{CELL DEATH}

The balance between cell proliferation and death allows multicellular organisms to model their shape during development and to maintain their own homeostasis in adulthood. Cell death might be accomplished in various ways: apoptosis, autophagy-associated cell death, necrosis, mitotic 
TABLE 1

Proapoptotic Activity of TG2 in Cells and Tissues under Physiological and Pathological Conditions

\begin{tabular}{llc}
\hline Cells/Tissue & \multicolumn{1}{c}{ Stimulus } & Reference \\
\hline $\begin{array}{l}\text { Embryonic and adult tissues } \\
\text { Embryonic fibroblasts }\end{array}$ & STS & {$[40]$} \\
$\begin{array}{l}\text { Periderm cells } \\
\text { Thymocytes }\end{array}$ & Various & {$[71]$} \\
Limb development & & {$[72,73]$} \\
Erythrocytes & $\mathrm{Ca}^{2+}$ & {$[74,75]$} \\
Mammary gland & Hormones & {$[76]$} \\
& & {$[77]$} \\
Experimental settings & Thapsigargin & \\
Striatal neurons & RA & {$[78]$} \\
Macrophages & RA & {$[79]$} \\
Smooth muscle & Ethanol & {$[80]$} \\
Hepatocytes/liver & Ca ${ }^{2+}$ & {$[70]$} \\
Cardiomyocytes & Hormones & {$[81,82]$} \\
Frog liver & Camptothecin & {$[83]$} \\
Keratinocytes & Light & {$[84]$} \\
Photoreceptors & Lead Nitrate & {$[85]$} \\
Hepatocytes & & {$[86,87]$} \\
Pathological settings & HIV & {$[88,89]$} \\
Lymph nodes & & \\
Encephalitis & Ischemia & {$[90,91]$} \\
Hippocampus & Huntington & {$[93]$} \\
Brain & Colitis & {$[94]$} \\
Myoenteric neurons & Parkinson & \\
Dopaminergic neurons & &
\end{tabular}

catastrophe, anoikis, excitotoxicity, Wallerian degeneration, and cornification of the skin [96]. The end point of each of these processes consists in the removal of the dying/dead cells from the living tissues through the action of professional or nonprofessional phagocytes. This final process is of utmost importance both for development and homeostasis of organisms as well as for preventing the onset of autoimmune pathologies [97, 98].

During the last 20 years, most of the morphological and biochemical aspects of apoptosis, necrosis, and autophagy-associated cell death have been successfully characterized. Cell death by apoptosis is characterized by well-defined morphological changes, such as plasma membrane blebbing, chromatin condensation, nuclear fragmentation, and the final formation of 
the apoptotic bodies [99]. These drastic morphological changes are associated with several biochemical ones, such as phosphatidylserine exposure on the outer leaflet of the plasma membrane, changes in the mitochondrial membrane permeability, and the release of the intermembrane mitochondrial proteins [100]. All these changes lead to the activation of effector caspases and caspases-activated DNase, which results in DNA cleavage [101]. These events lead the cell to be dismantled and eliminated selectively, without affecting tissue's integrity.

Autophagy, originally described by Christian De Duve in 1966 [102, 103], has been known to be a survival mechanism activated by cells subjected to nutrients or growth factors deprivation. Autophagy allows cells to self-digest their own macromolecules and organelles, through the activity of their lysosomes, in order to recycle metabolites and provide a source of energy. Nevertheless, autophagy is a tightly regulated process and the characterization of the molecular players involved in its control and execution revealed the existence of a complex cross talk between autophagy and apoptosis [104]. In fact, under prolonged stress conditions, such as in neurodegenerative disease or cancer, autophagy might play a complex role as a death process in itself or show features of apoptotic or necrotic cell death [105].

Necrosis is a process characterized by the swelling of the intracellular organelles and the rupture of the plasma membrane. The release of proteolytic enzymes from lysosomes, together with the activation of intracellular enzymes, leads to cell demolition. This event is associated with the release of the intracellular material and, in most cases, with the onset of inflammation processes [106]. Necrosis is usually considered a non-programmed form of death, resulting from metabolic failure associated with a rapid depletion of ATP, such as after ischemia and stroke. The alteration of the permeability of cellular membranes results in an increased intracellular concentration of calcium ions, which activate cellular proteases, such as calpains and cathepsins. Intriguingly, if the calcium efflux crosses the plasma membrane, it might trigger necrosis, while if the calcium comes from the endoplasmic reticulum (ER), it might trigger apoptosis $[107,108]$. ATP also plays a different role in the two processes, as energy is necessary for the activation of various apoptosis effectors (i.e., the apoptosome), while ATP depletion shifts cells from apoptosis to necrosis. Accumulating evidence indicate that necrosis is also more ordered, if not controlled, than was originally thought [107].

These three major and most characterized types of cell death are not mutually exclusive. In fact, the type and intensity of the death signal, the ATP concentration, the cell type as well as many other factors are all able to 
determine which type of death occurs and, eventually, the shift from necrosis to apoptosis and vice versa [109]. In addition, the blockade of one of these cell death pathways rather than preventing the destruction of the cell may actually activate an alternative pathway [110-112]. This picture is supported by the growing numbers of evidence involving protein factors, such as p53 and Bcl-2 family members, which are able not only to modulate the onset of cell death but also to determine the cell's choice between the various types of death.

To date, more than 500 publications have shown that TG2 is involved both in apoptosis and autophagy. The detection of the enzyme upregulation is used as a marker of apoptosis for in vivo studies [113]. Although the molecular mechanism(s) of its action is still lacking, it is clear that TG2 can play both pro- and anti-death functions, depending on the cell type, the subcellular localization, and the type of the death stimulus. In general, under physiological conditions, TG2 plays a proapoptotic function (see Table 1), while, in highly transformed cells, it can also switch its activity toward cell protective functions. It is not clear how this is possible and which of the various TG2 activities and/or protein partners are involved in this prosurvival action. Indeed, in some tumors, TG2 expression has been shown not only to protect cells from death, but also to carry out a proapoptotic function (see Table 2). This is probably due to the different cell clones derived from the original tumor as well as to their adaptation to in vitro culture conditions or to the apoptotic stimulus used (i.e., agents, concentrations, time frame, etc.). An explanation for these controversial results could be found in the recently described role played by TG2 in autophagy (see the "Autophagy" section). In fact, it is well-established that autophagy can play an important survival role in cancer cells, its downregulation constituting a new frontier for cancer chemotherapy.

\section{A. TG2 AS A PROAPOPTOTIC FACTOR}

Apoptosis is a genetically programmed and controlled form of cell death, accomplished through the activation of specific intracellular pathways in response to various death stimuli. Two distinct but convergent pathways have been extensively characterized: (1) the extrinsic and (2) the intrinsic pathway [106]. The extrinsic or "death-receptor" pathway receives and decoys signals coming from outside the cell, through the activation of specific plasma membrane proteins belonging to the tumor necrosis factor (TNF) receptor family, the "death receptors." The binding of the TNF ligand to its 
TABLE 2

Proapoptotic and Prosurvival Functions of TG2 in Cancer

\begin{tabular}{|c|c|c|c|c|c|}
\hline \multicolumn{3}{|c|}{ Proapoptotic } & \multicolumn{3}{|c|}{ Antiapoptotic } \\
\hline Cells/Tissue & Stimulus & Reference & Cells/Tissue & Stimulus & Reference \\
\hline $\begin{array}{l}\text { Breast cancer } \\
\quad(\text { MDA-MB-231) }\end{array}$ & Calphostin C & [114] & Ovarian cancer & various & {$[115,116]$} \\
\hline Epithelial tumors & Theophyllin & [117] & Caki & TRAIL & [118] \\
\hline Pancreatic cancer & A23187 & [119] & Ovarian cancer & Cisplatin & [120] \\
\hline Myeloma & RA & {$[121,122]$} & Meningioma & Radiation & [123] \\
\hline U937 & RA & [69] & Glioblastoma & BCNU & [124] \\
\hline Lung cancer & IFN alpha & [125] & $\begin{array}{l}\text { Pancreatic } \\
\text { cancer } \\
\text { (PDAC) }\end{array}$ & RA & {$[126,127]$} \\
\hline Neuroblastoma & RA & {$[128,129]$} & Breast cancer & Doxorubicin & [130-132] \\
\hline $\begin{array}{l}\text { Carcinoma cells } \\
(\mathrm{HeLa})\end{array}$ & $\begin{array}{l}\text { RA and } \\
\text { DFMO }\end{array}$ & [129] & $\begin{array}{l}\text { Nonsmall cell } \\
\text { lung cancer }\end{array}$ & Cisplatin & [133] \\
\hline $\begin{array}{l}\text { Pancreatic } \\
\text { adenocarcinoma }\end{array}$ & RA & {$[134]$} & Neuroblastoma & TNF alpha & [135] \\
\hline
\end{tabular}

receptor triggers a conformational change in the receptor itself and induces the intracellular recruitment of modulator proteins, such as FADD and cFLIP, which assemble to form the DISC complex at the cytoplasmic side of the plasma membrane. The DISC complex is able to recruit and activate caspase 8 , which ultimately activates the executioner caspase 3 [136].

The intrinsic or mitochondrial pathway receives and decoys signals coming from inside the cell, such as increased intracellular reactive oxygen species (ROS), DNA damage, the unfolded protein response, and growth factors deprivation. All these initiators lead to increased mitochondrial permeability and promote the release of proteins from the mitochondrial intermembrane space into the cytosol $[100,137]$. The release of proapoptotic factors (e.g., cytochrome $c$ ) and of antagonists of cytosolic antiapoptotic proteins (i.e., SMAC/DIABLO) allows the activation of the APAF-1 complex, which recruits and activates caspase 9. The two pathways converge, since the activated caspase 8 and 9 in turn activate the executioner caspase 3 , 6 , and 7 , which dismantle the cell by cleaving various protein substrates and activate DNases [106]. The two pathways are not only convergent at the final steps, but are also cross talking at mitochondrial level. It has been shown that, death-receptors may activate the release of cytochrome $c$ via the caspase 8-dependent processing of the proapoptotic BH3-only protein Bid [138]. 
At once very delicate and highly coordinated, the regulation of these pathways involves cellular organelles, such as mitochondria and the ER, as well as specific protein factors, such as the members of the Bcl-2 family. The proteins belonging to this family are characterized by the presence of shared domains, the Bcl-2-Homology $(\mathrm{BH})$ domains, which allow them to interact both with each other and with other proteins, in order to modulate the permeabilization of the outer mitochondrial membrane $[139,140]$. These proteins might then behave as pro- or anti-apoptotic factors, by acting on mitochondrial and ER membranes [141]. During the last 5 years, the characterization of a large number of proteins sharing homology with the $\mathrm{BH} 3$ domain of Bcl-2 has greatly increased the number of the member of the $\mathrm{BH} 3$-only protein family. All these newly discovered proteins can act as inducers or sensitizers of apoptosis, even if normally they perform different intracellular activities [142-146].

The initial observation that both TG2's levels and activity were induced during apoptosis, both in vitro and in vivo (see Table 1 and $[52,147]$ ), suggested a strong involvement of TG2 in cell death. An early hypothesis postulated that the formation of highly stable cross-links between glutamine and lysine residues of cellular proteins stabilized the dying cell and prevented the release of the cytosolic components $[67,148]$. The observed induction of TG2 gene expression during apoptosis onset in vivo [53, 83, 149] was coupled with in vitro observations of increased enzymatic sensitivity [41, 128, 149] as well as protection [69] against apoptosis upon induction or downregulation of TG2 expression, respectively. Such evidence, suggesting the enzyme acting as a proapoptotic factor, was further supported by the discovery that TG2 might localize on mitochondria where it could act both as a $\mathrm{BH} 3$-only protein [51] or as a PDI $[25,40]$. The $\mathrm{BH} 3$-only proteins belong to the Bcl-2 family and might exert their proapoptotic activity by activating Bax and Bak in order to induce the mitochondrial membrane permeabilization. TG2 possesses a domain (Figure 1), which shares more than $70 \%$ of homology with the consensus for the $\mathrm{BH} 3$ domain; it is through this domain that the enzyme is able to interact with Bax and Bak, which might be favored in their mitochondrial localization and proapoptotic activity (Figure 2). Activation of the TG2's cross-linking activity, upon apoptosis induction, results in the TG2-dependent polymerization of these proapoptotic factors on the mitochondrial outer membrane, as well as to a faster loss of the mitochondrial membrane potential and to the execution of the apoptotic program [51]. It has also been shown that the interaction of Bax with Adenine Nucleotide Translocase 1 (ANT1), which represents an essential step in the opening of 
the mitochondrial permeability transition pore, is largely reduced in MEFs lacking TG2, thus resulting in the impairment of apoptosis [40]. Another aspect of the complex interaction between TG2 and mitochondria that might lead to a proapoptotic outcome, in drug-resistant cancer cells, is related to the localization of nucleophosmin 1 (NPM1) in the cytosol. NPM1 gene mutations causing aberrant cytosolic expression of nucleophosmin are the most frequent genetic alteration observed in acute myeloid leukemia (AML), such an alteration being found in about $30 \%$ cases. It has recently been shown that NPM1 expression enhances the levels of p53 in the nucleus but reduces p53 levels in mitochondria. It is well known that the presence of p53 in mitochondria plays an important role in stress-induced apoptosis, suggesting that NPM1 may protect cells from apoptosis, by reducing the mitochondrial level of p53 [150]. Interestingly, it has been reported that NPM1 acts a TG2 substrate [133], suggesting that TG2 can inhibit NPM1 accumulation in the cytoplasm, through its polymerization, and thus protecting cells from apoptosis, by reducing the mitochondrial level of p53 (Figure 2).

Another interesting finding is that TG2 might also localize in the mitochondrial intermembrane space, where, through its PDI activity, it may modify and stabilize the assembly and the activity of some members of the respiratory chain complexes as well as of ANT1, in the inner mitochondrial membrane $[25,40]$. In fact, the ablation of the TG2 gene in mice leads to an impairment of the respiratory complex chain coupled with a decrease in the ATP production and an effect on the cell's sensitivity towards death induction, dependent on the cell type and on the kind of death stimuli [151,152].

Further important evidence, highlighting the proapoptotic function of TG2 and its effect on mitochondria, has been reported in pancreatic ductal adenocarcinoma (PDAC), a lethal malignant disease with poor long-term survival rates. In these highly transformed cells, the activation of endogenous TG2, by the calcium ionophore A23187, results in rapid and spontaneous apoptosis, which is associated with the release of the apoptosis-inducing factor (AIF). The translocation of AIF from mitochondria to the nucleus leads to the execution of a caspase-independent form apoptosis [119].

The action exerted by TG2 at mitochondrial level highlights a more general contribution of this multifunctional enzyme both to the maintenance of mitochondrial physiology and to the modifications taking place during apoptosis onset and execution $[147,153]$. This aspect is of potential relevance in all those pathologies, such as neurodegenerative diseases and stroke, in which the mitochondrial functionality plays a crucial role in the cell's decision between survival and death. In addition, TG2 overexpression leads to 
the accumulation of ROS associated with a large depletion of GSH [41]. In keeping with these findings, GST P1-1 acts as a very efficient TG2 substrate both in cells and in vitro, and its TG2-dependent polymerization causes a functional inactivation of the enzyme [62]. GSH depletion occurs during the early phases of apoptosis and the functional inactivation of GST P1-1, by TG2-catalyzed oligomerization, indicates a further potential proapoptotic role for TG2 (Figure 2).

TG2 is largely localized in the cytosol at the level of the plasma membrane, the cytoskeleton, the ER, and the mitochondria, although, depending on cell type, a small amount of the enzyme is also present in the nucleus [154]. It has been shown that both the intracellular localization and the activation of its transamidating activity are important factors in the modulation of TG2's effects on apoptosis induction (Figures 2 and 3). Transfection of cells with cDNAs coding for wild type or mutant TG2, which lack the transamidating activity and were targeted to different intracellular compartments, confirmed the proapoptotic nature of the cytosolic form of TG2. Nevertheless, the nuclear localization of cross-linking-inactive TG2 reduced apoptosis, thus indicating how the intracellular localization influences its effect on cell death. Further evidence derives from the observation that the

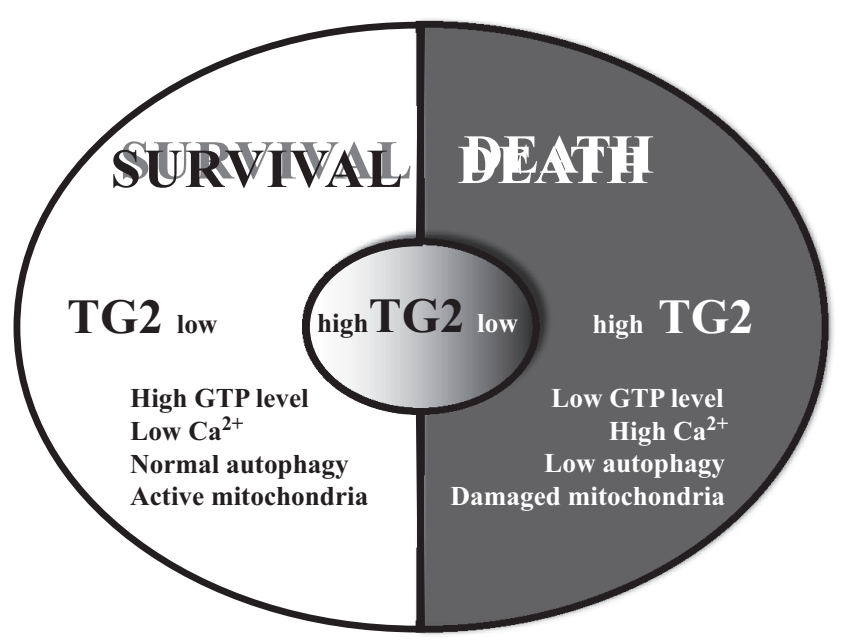

FIGURE 3. The pro-survival and pro-death features of TG2 rely on its localization in the cytosol or in the nucleus. 
DAP-like kinase (DLK) undergoes TG2-dependent oligomerization in cells treated with calphostin C $[114,155,156]$. DLK is a nuclear serine/threoninespecific kinase, belonging to the subgroup of the mixed-lineage kinases (MLKs). These proteins act as key regulators of the stress-activated c-Jun $N$-terminal kinase (JNK) mitogen-activated protein kinase (MAPK) signaling pathway. The induction of apoptosis by DLK requires its relocation to the cytoplasm and its association with the actin cytoskeleton, which is achieved through the interaction with the proapoptotic protein Par-4 [157]. DLK overexpression in neural cells and in sympathetic neurons induces apoptosis via the mitochondrial pathway. Conversely, overexpression of a dominant-negative form of DLK in the same cells prevents apoptosis, thus indicating that DLK is involved in the control of cell death [158]. Interestingly, the TG2-dependent oligomerization of DLK occurs early in the apoptotic response and significantly enhances its kinase activity and consequently its ability to activate the JNK pathway [114]. Moreover, functional studies demonstrate that TG2-mediated oligomerization of wild-type DLK sensitizes cells to calphostin $\mathrm{C}$-induced apoptosis, while cross-linking of a kinase-inactive variant of DLK does not [114]. These findings suggest that TG2 proapoptotic activity is at least partially mediated by the oligomerization and activation of the proapoptotic kinase DLK, which in turn will activate the proapoptotic JNK pathway (Figure 2). Recently, it has been shown that TG2 mediates alcohol-induced hepatocytes apoptosis in vivo by cross-linking SP1 [70]. This TG2-dependent modification leads to SP1 inactivation and results in a reduction of c-Met expression, which is required for hepatocytes cell survival.

\section{B. TG2 AS AN ANTIAPOPTOTIC FACTOR}

TG2 acts as a proapoptotic factor under physiological conditions, during both embryonic and adult life. Conversely, in transformed cells, the enzyme can also play a dual role, acting as an antiapoptotic factor. This alternative behavior has often been described in the same tumor type, such as neuroblastoma, pancreatic, and ovarian cancer. Such observations suggest that the switch between the two opposite actions exerted by the enzyme might be dictated by environmental as well as genetic background of the cell line studied. Nevertheless, during recent years, various papers have reported the ability of TG2 to perform as a G protein [20], as a kinase [21], and as a modulator of the cell/ECM adhesion processes [159]. The prevalence of a specific activity coupled with different localization, both inside and outside the cell, 
very likely account for the switch between pro- and anti-apoptotic functions of TG2 $[153,154,120,160,161]$. This differential regulation of cell death by TG2 is highly relevant in cancer (see Table 2), in which TG2's antiapoptotic activity might lead to the survival of cells that have to be eliminated by the organism. Some clues about the possible mechanisms at the basis of this prosurvival function of TG2 have been recently published [161-165]. We first demonstrated that TG2 post-translationally modifies the Rb protein, an important suppressor of apoptosis [66]. Recently, it has been proposed that $\mathrm{TG} 2 / \mathrm{Rb}$ interaction increases significantly, concomitant with an attenuation of apoptosis. The TG2/Rb interaction is emerging as an important aspect of the antiapoptotic effects of TG2. In fact, in cells undergoing apoptosis, $\mathrm{Rb}$ is degraded by the action of caspases, this degradation proving to be blocked when cells have been pretreated with RA, an important transcriptional inducer of TG2 [166]. Experiments performed with $\mathrm{Rb}^{-/-}$fibroblasts demonstrated that $\mathrm{Rb}$ is required for TG2 to exhibit antiapoptotic activity in response to RA treatment. These results imply that the ability of TG2 to modify Rb represents a key step for TG2's survival activity. It has also been hypothesized that TG2 might protect tumor cells against apoptosis by translocating into the nucleus. However, controversy remains as to whether the transamidating activity of nuclear TG2 is required to bind and protect $\mathrm{Rb}$ from the degradation occurring during apoptosis.

It has been shown that the exposure of TG2-expressing cells to the phosphoinositide 3-kinase (PI3K) inhibitor LY294002 reduces the ability of the enzyme to bind GTP. This observation suggests that PI3K regulates the shift between the transamidating and the GTP binding activity of TG2, thus inhibiting TG2's cross-linking activity (Figures 1 and 3) [167]. These findings imply that PI3K activity, a well-established cell survival factor, is required for the modulation of the GTP binding activity of TG2. Accordingly, TG2 expression and its GTP binding activity prove to be very high in a number of transformed cell lines. Interestingly, the switch between the prosurvival TG2/GTPase and the proapoptotic transamidating activity can be influenced by the Ras-ERK pathway [168]. These observations suggest that the TG2 pro- and anti-apoptotic conflicting functions may be regulated by conformational changes of the protein. In fact, the binding of GTP can convert the enzyme from an "open" cell death-promoting to a "closed" protein conformation able to provide protection against apoptotic stimuli (Figure 1). This hypothesis has been supported by the observation that the expression of full-length TG2 in tumor cells confers protection against cell death, while the expression of a shorter version of TG2, truncated at the $3^{\prime}$ end and 
unable to bind GTP, turns out to be cytotoxic [169]. The proapoptotic activity of the short form of TG2 does not rely on its transamidating activity, because the mutation of the cysteine 277 residue, essential for catalyzing this reaction, does not compromise the ability of this short form of TG2 to induce cell death. Notably, a shorter TG2 transcript, encoding for a truncated form of TG2 (TGase-S), which shows strong proapoptotic activity, has been identified from the brains of Alzheimer's patients. This TGase-S exhibits no detectable GTP-binding capability, further suggesting that TG2's ability to induce cell death is due to its inability to bind GTP. These results are particularly relevant considering TG2's well-known involvement in neurodegenerative diseases (see below).

\section{AUTOPHAGY}

Autophagy is the cellular metabolic pathway implicated in the recycling of portions of cytosol as well as in the removal of superfluous or damaged organelles. In addition to proteins, this transport route is uniquely able to catabolize other cellular constituents such as lipids, carbohydrates, and nucleic acids. This essential biological process occurs at a basal level in most tissues and contributes to the routine turnover of cytoplasmic components of the cell $[170,171]$. However, it can also be massively induced by a change in the environmental conditions or by cytokines and other signaling molecules, to help the cell to adapt and/or cope with various physiological and pathological situations [172]. Autophagy is very important for cellular remodeling and development and is also involved in preventing ageing and controlling cell growth [173]. Moreover, it plays an important role in several human diseases, such as cancer, neurodegeneration (Huntington's diseases (HD), Parkinson's diseases (PD), and Alzheimer's diseases (AD)), and muscular disorders [105, 174].

Autophagy is also used by cells to defend themselves from invasion by pathogenic bacteria such as Mycobacterium tuberculosis, viruses such as the Herpes simplex and the Tobacco mosaic viruses, and intracellular parasites like Toxoplasma gondii $[105,175,176]$. Finally, autophagy may play a controversial role as a cell death mechanism (i.e., type II programmed cell death) and in some cases appears to be regulated in conjunction with apoptosis [177, 178].

To date, three forms of autophagy have been defined, according to how lysosomes receive the material to be degraded [106, 179]. In macroautophagy, a double membrane structure, called autophagosome, envelops 
the cargo and fuses with the lysosome (Figure 4). In microautophagy, the lysosome directly engulfs the material by means of an invagination of the organelle's membrane. In chaperone-mediated autophagy, heat shock cognate proteins deliver the substrates to the lysosome. The most characterized form of autophagy is macro-autophagy in which cells are characterized by the formation of double membranes autophagic vacuoles, containing cytoplasmic material (cytosol and/or organelles), which are then delivered to fusion with lysosome, in order to achieve bulk degradation [180]. This process might occur in a generalized fashion; alternatively, it might target specific organelles, such as mitochondria and ER, thereby eliminating supernumerary, outlived, or damaged structures in the stressed cell [181]. Macro-autophagy's initial steps include the formation (vesicle nucleation) and the expansion (vesicle elongation) of an isolation membrane, which is also called phagophore. The edges of the phagophore then fuse (vesicle completion) in order to form the autophagosome, a double-membraned vesicle that sequesters the cytoplasmic material. These steps are followed by the fusion of the autophagosome with a lysosome, in order to form an autolysosome, where the captured material, together with the inner membrane, is degraded (Figure 4).

Nutritional status, hormonal factors, and other cues such as temperature, oxygen concentrations, and cell density are important factors involved in the control of autophagy onset. At the molecular level, one of the key regulators of the autophagy process is the target of rapamycin, mTOR kinase, this is the major inhibitory signal that shuts off autophagy in the presence of growth factors and abundant nutrients [182].

The class I PI3K/Akt signaling molecules link receptor tyrosine kinases to TOR activation and thereby repress autophagy in response to insulinlike and other growth factor signals [183]. Some of the other regulatory molecules that control autophagy include 5'-AMP-activated protein kinase (AMPK), which responds to low energy state; the eukaryotic initiation factor $2 \alpha(\mathrm{eIF} 2 \alpha)$, which responds to nutrient starvation, double-stranded RNA, and ER stress; the BH3-only proteins, which interfere with the Bcl-2/ Bcl-X $\mathrm{L}_{\mathrm{L}}$ inhibition of the Beclin 1/class III PI3K complex; the tumor suppressor protein $\mathrm{p} 53$; the death-associated protein kinases; the ER membraneassociated protein Ire-1; the stress-activated kinase, c-Jun- $N$-terminal kinase; the inositol-trisphosphate receptor; GTPases; Erk1/2; ceramide; and calcium [184-187].

The characterization of autophagy at molecular level, extensively carried out in yeast, revealed the existence of more than 20 genes, known as the ATG genes, downstream of mTOR kinase. Those genes encoded evolutionarily 


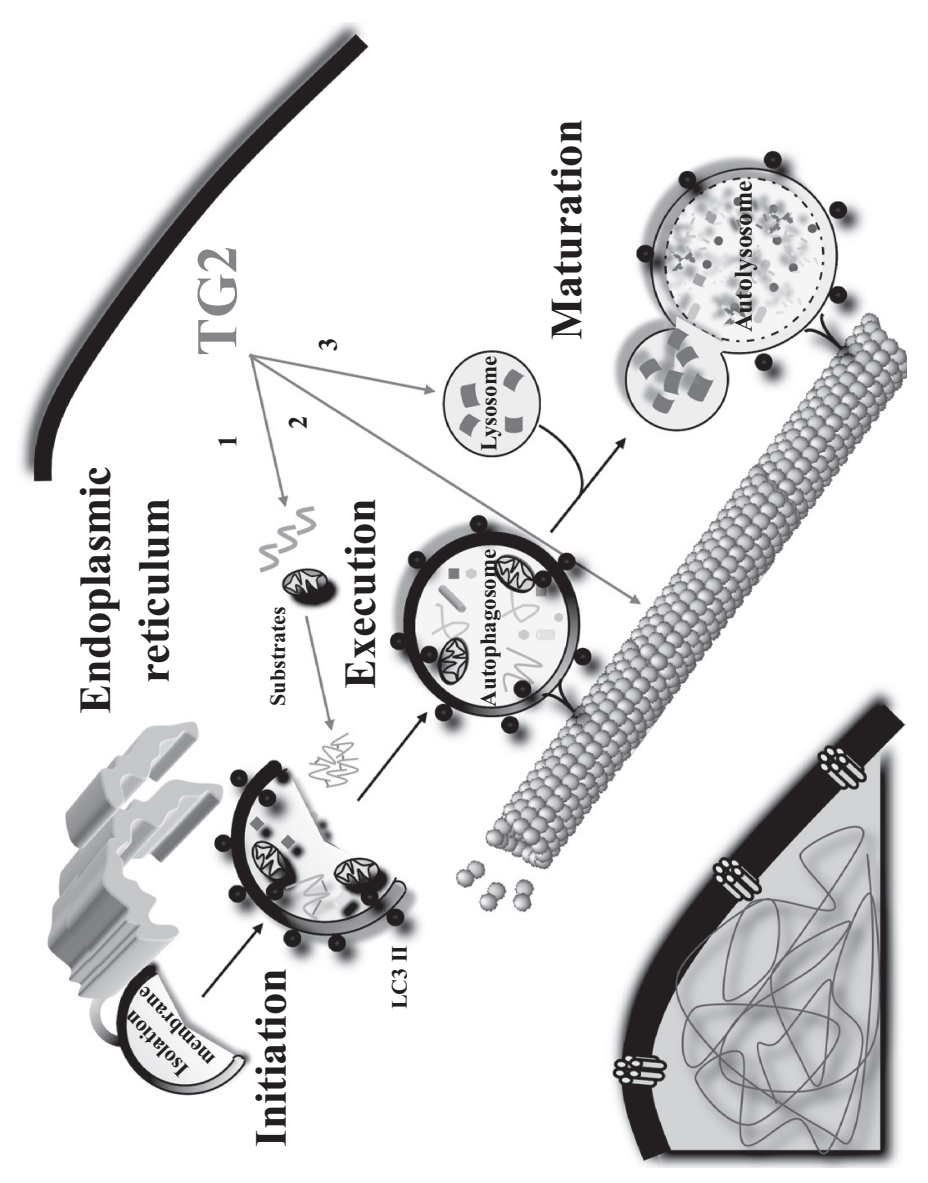

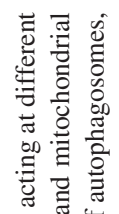

진휴

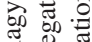

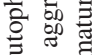

ส

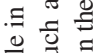

홍

\%

完蓠

突寻

है के

Oิ

ने के

Е

苍总总

总

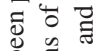

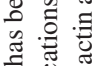

프

它告

类焉

플 증

希洁

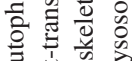

紊完

웡 훙

$\Xi \cong \stackrel{0}{=}$

용

월

흐웡워

응

\&

㽦沓

퀘크

तु 용

등

딩 $\widehat{\theta}$

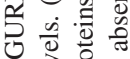

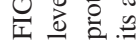


conserved proteins essential for the execution of the autophagy process [171]. These proteins include a protein serine/threonine kinase complex, which responds to upstream signals such as mTOR kinase (Atg1, Atg13, Atg 17); a lipid kinase signaling complex, which mediates vesicle nucleation (Atg6, Atg14, Vps34 and Vps15); two ubiquitin-like conjugation pathways, which mediate vesicle expansion (Atg8 and Atg12); a recycling pathway, which mediates the disassembly of Atg proteins from mature autophagosomes (Atg2, Atg9, Atg 18); and vacuolar permeases, which permit the efflux of amino acids from the degradative compartment (Atg22).

In mammals, proper fusion with autophagosomes requires proteins that act more generally in lysosomal functions, such as the lysosomal transmembrane proteins, LAMP-2, and CLN3. Accordingly, proper degradation of the autophagosomal contents requires the activity of lysosomal cysteine proteases and cathepsins $\mathrm{B}, \mathrm{D}$, and $\mathrm{L}$.

The detection and manipulation of autophagy pathways has been greatly enhanced by the identification of, first, the signals able to induce autophagy and, second, the genes involved in carrying out this process. One of the key events occurring in autophagy is the phosphatidyl-ethanolamine (PE) conjugation of yeast Atg8 or mammalian LC3 protein. The result of this reaction is a nonsoluble form of Atg8 (Atg8-PE) or LC3 (LC3 II) that stably associates with the membrane of the autophagosome. This event allowed researchers to detect the onset of autophagy either by assessing the generation of Atg8-PE or LC3 II, on western blot, or by observing, with fluorescence or confocal microscopy, the localization pattern of fluorescently tagged Atg8 or LC3 [188]. These approaches must be coupled with ancillary measures to discriminate between two physiologically distinct scenarios: (1) the increased autophagic flux, without impairment in autophagic turnover, versus (2) the impaired clearance of autophagosomes, which results in a functional defect in autophagic catabolism.

On the other hand, autophagy can be pharmacologically induced by targeting the following elements: (1) negative regulators of the process, such as mTOR, with rapamycin [187]; (2) proteins involved in the autophagosome formation, such as the class III PI3K, with 3-methyladenine; (3) the fusion of autophagosomes with lysosomes, by inhibiting the lysosomal proton pump with bafilomycin A1 or by decreasing the lysosomal protease activities with $\mathrm{NH}_{4} \mathrm{Cl}$ that neutralize lysosomal $\mathrm{pH}$ [189].

Very little is known about the relationship existing between TG2 and the execution/regulation of the autophagy process. Previous studies, carried out in a mice model for Huntington's disease (HD), suggested a possible involvement of TG2 in autophagy associated with the neurodegenerative processes 
observed in this disease [92]. In fact, the analysis of brains belonging to patients and animals suffering from CAG-repeat-based genetic diseases, such as HD, revealed clear neurodegenerative features unassociated with any hallmark of classical apoptosis $[190,191]$. Degenerating neurons show lysosome-associated responses, including induction of autophagic granules and electron-dense lysosomes, thus indicating that mutated huntingtin can induce autophagy. Therefore, autophagy could be the major route for the clearance of intracellular misfolded protein aggregates that underlie these neurodegenerative diseases. Analysis of the TG2 $2^{-/} / \mathrm{HD}$ transgenic mice showed that HD onset is associated with a large reduction in nonapoptotic cell death and with an increased number of nuclear protein inclusions, suggesting an impairment in their clearance by means of autophagy [92]. In keeping with this hypothesis, ablation of TG2 protein has recently been shown to result in an evident accumulation of LC3 II on pre-autophagic vesicles, pointing to a marked induction of autophagy [192]. By contrast, the formation of the acidic vesicular organelles was very limited, as detected by the lack of acidification of the autophago-lysosomes observed in TG2 $2^{-1-}$ MEFs, after acridine orange staining. These findings suggest an impairment in the autophagosomes maturation process. This conclusion is supported by the fact that treatment of TG2 proficient cells with $\mathrm{NH}_{4} \mathrm{Cl}$, in order to inhibit lysosomal activity, results in a marked accumulation of LC3 II and damaged mitochondria, as also observed in TG2 $2^{-1-}$ cells. It is well known that autophagy plays a crucial role in the turnover of cellular organelles; in particular, it has been proposed that autophagy selectively degrades dysfunctional mitochondria [193]. Taken together, these data indicate a role for the TG2-mediated post-translational modifications of proteins involved in the fusion between autophagosomes and lysosomes. In fact, a drastic reduction in the colocalization between autophagosomes and lysosomes has been detected in TG $2^{-l-}$ cells, even in presence of the inhibitor of intralysosomal protein degradation. It is worth noting that the inhibition of the transamidating activity of TG2, by means of the specific inhibitor R283 [194], results in a marked decrease of the number of acidic vesicular organelles, possibly highlighting the TG2's cross-linking activity as an important player in the autophagy pathway. In line with this finding is the use of a well-known competitive inhibitor of transglutaminase, the autofluorescent compound mono-dansyl-cadaverine (MDC), for in vivo labeling of autophagic vacuoles. MDC accumulates as a selective marker for autophagic vacuoles under in vivo conditions and is not present in the early and late endosome. Interestingly in this regard, the presence of a latent transglutaminase activity in rat liver lysosomes has been reported [195]. 
TABLE 3

TG2 Protein Substrates Involved in Autophagy (For reference go to http://genomics.dote.hu/wiki/ [198].)

\begin{tabular}{ll}
\hline Regulatory Proteins & \multicolumn{1}{c}{ Autophagy Substrates } \\
\hline TGF-beta & Huntingtin \\
Bax & Alpha synuclein \\
Rho A & Ataxin 1 \\
Bip & Hsp 70 \\
Sinapsin 1 & Hsp 90 \\
Rock & Valosin-containing protein \\
& Parkin \\
& Ubiquitin \\
& Phosphorylase kinase \\
& Fructose 1,6-bisphosphatase \\
& Phosphoglycerate dehydrogenase \\
& GAPDH \\
\hline
\end{tabular}

The involvement of TG2 in autophagy has also been shown in highly metastatic pancreatic carcinoma cells. In this cells, the inhibition of PKC- $\delta$, by rottlerin, or the knockdown of TG2 protein, by siRNA, leads to the accumulation of autophagic vacuoles in the cytoplasm and a marked induction of LC3 II [196].

Although the molecular mechanism(s) by which TG2 can regulate autophagy is not yet known, one attractive hypothesis is that this effect could be exerted at the level of cytoskeleton (Figure 4). Indeed, TG2-dependent posttranslational modification of the cytoskeleton's major components, such as tubulin, actin, and vimentin, has been shown to be able to influence its regulation [8]. A functional cytoskeleton is of fundamental importance for the proper intra-cellular traffic of the autophagic vesicles and for their fusion with lysosomes. Accordingly, it has been shown that, in mammalian cells, the disruption of the microtubule network results in a delay, rather than a complete block, in the autophagy process [197].

Finally, it is relevant to note that several TG2 candidate protein substrates (Table 3) have been shown to be enriched on the autophagosome membrane; this provides further evidence that TG2-catalyzed post-translational modifications may have a role in the maturation of the autophagosomes [192].

\section{TG2 IN DISEASES}

Considering the multifunctionality and the unique cellular biochemistry of TG2, it comes as a surprise that homozygous deletion of TG2 does not result 
in an embryonic lethal phenotype [199, 200]. The homozygous null animals are viable, of normal size and weight, and born with Mendelian frequency. The most probable explanation for the lack of severe phenotypes is that other TGs in mammalian tissues can compensate for the loss of TG2. However, such compensation is partial, since the other mammalian TGs do not have all the enzymatic activities carried out by TG2.

In line with this, several alterations have been detected in $\mathrm{TG} 2^{-/-}$mice, especially under stressful and pathological conditions. In fact, decreased adherence of primary fibroblasts [200] and impaired wound healing, related to altered cytoskeleton dynamics of fibroblasts, have been observed in these mice, consistent with the suggested extra- and intra-cellular functions of TG2. Moreover, when cell death is induced in $\mathrm{TG}^{-/-}$mice, the clearance of apoptotic cells by phagocytosis is defective in the thymus and liver and both inflammatory and autoimmune reactions develop [201].

TG2-deficient mice also show glucose intolerance and hyperglycemia, because of a reduced insulin secretion, a phenomenon similar to a subtype of diabetes called MODY (maturity-onset diabetes of the young) [202]. Furthermore, the ablation of TG2 in mice causes an increased vulnerability of cardiomyocytes to ischemia/reperfusion injury [152]. This effect is associated with a decreased capacity of $\mathrm{TG}^{-I-}$ mice to synthesize ATP, due to a reduced activity of mitochondrial complex I [151].

All the major human diseases are associated with dysregulation of pathways controlling cell death and survival. As previously described, apoptosis and autophagy constitute the two processes through which superfluous, damaged, or aged cells and/or organelles are eliminated. The functional relationship between these two processes is highly complex. In fact, autophagy constitutes a stress adaptation that in general avoids cell death, whereas in different settings, it might constitute an alternative cell-death pathway [104]. Because of TG2's involvement in these two basic cellular events, the enzyme has been clearly implicated in the pathogenesis of a number of pathological conditions, such as celiac sprue [203], neurodegenerative disorders [204], diabetes [202], liver cirrhosis and fibrosis [205, 206], renal scarring [207], and certain types of cancer [208].

\section{A. INFLAMMATORY DISEASES}

Many reports have shown that the expression of TG2 is increased in inflammatory diseases and/or autoimmune diseases [209]. Interestingly, both apoptosis and autophagy have been shown to play an essential role in either the pathogenesis or the response to these diseases. Results obtained in recent 
years have shown a participation of TG2 in these self-eating and self-killing pathways, thus making TG2 a potential therapeutic target.

A characteristic feature of chronic inflammatory diseases is the persistent presence of apoptotic cells resulting from impaired phagocytosis [210, 211]. It has been shown that the lack of TG2 function is associated with a defective clearance of apoptotic cells. In fact, $\mathrm{TG} 2^{-1-}$ mice showed a significant perturbation in the phagocytosis of apoptotic cells. The long-term consequence of the absence of the enzyme results in the development of splenomegaly, autoantibodies, and glomerulonephritis [201]. Under physiological conditions, macrophages play a pivotal role in both recognition and clearance of apoptotic cells. An essential aspect of this process is the absence of an inflammatory response [212]. The lack of TG2 results in an impaired capacity of macrophages to engulf apoptotic cells and also affects the release of proinflammatory cytokine from macrophages, leading to an abnormal inflammatory response. Accordingly, both TGF- $\beta$ and IL-12 regulations were significantly altered in the $\mathrm{TG} 2^{-1-}$ mice [213]. These results help to explain the autoimmune phenotype developed by these mice and suggest that TG2 is a key regulatory element of the anti-inflammatory features of apoptosis. Indeed, it has been reported that the production of inflammatory cytokines by macrophages requires the activation of the p38 MAPK pathway, in order to promote the stability and availability of inflammatory cytokine transcripts for translation [214, 215], whereas selective inhibitors of p38 MAPK prevent proinflammatory cytokine release [216]. In keeping with these findings, it is interesting to note that TG2 activity is required for the activation of p38 MAPKs. In fact, it has been shown that TG2 mediates the activation of RhoA and MAP kinase pathways during RA-induced neuronal differentiation of SH-SY5Y cells [60]. Consistent with these evidences, in TG2 $2^{-1-}$ mice, the expression of both IL-12 and sTNF-RI is significantly increased. Interestingly, the dysregulation of IL-12 has been described in a wide range of autoimmune-prone mouse models such as the TG2 ones [217-219].

The recently discovered function of autophagy in the ATP-dependent generation of engulfment signals and heterophagic removal of apoptotic corpses [220], highlights the potential role for autophagy in the prevention of inflammation and autoimmunity [174].

The inability to regulate inflammation is of great importance in the pathogenesis of sepsis, during which dysregulated inflammatory processes might induce organ's impairment and death. The progress from the disease to septic shock and death depends on a complex interaction of the inflammatory cascades with several intracellular signaling pathways [221, 222]. Inflammation 
and apoptosis appear to be closely linked in the immuno-pathogenesis of sepsis. Previously, it was generally thought that sepsis represented an unbridled immune response with excessive cytokine production. Now, increasing evidence suggest that extensive apoptotic death, leading to a depletion of the cells of the immune system, weakens patient's ability to eradicate infections. Recent findings show that apoptosis of the parenchymal cells in the lung, gut, and liver contributes substantially to the failure of these organs in response to sepsis. Hopefully, therapeutic approaches, involving the inhibition of the apoptotic processes, will prove capable of restoring necessary immune functions and improving the chances to survive the septic insult [223, 224]. TG2 expression has been reported to be induced by LPS in several tissues and organs [225-227]. TG2's possible contribution to the pathological inflammatory dysregulation occurring in septic shock has recently been investigated, demonstrating that TG2, acting at multiple levels, could be an important factor in the mechanism through which sepsis develops [228]. Hence, TG2 ${ }^{-1-}$ mice displayed enhanced survival to LPS challenge, the absence of TG2 being associated with profound reduction of the inflammatory response and attenuated organ damage. Although proinflammatory mediator's production is elicited in $\mathrm{TG} 2^{-1-}$ mice by LPS treatment, these mice have the capacity to restore the initial equilibrium. Activation of the nuclear transcription factor NF-kB plays a key role in the inflammatory process by inducing the transcription of proinflammatory mediators [229]. This activation is the result of phosphorylation and subsequent degradation of the inhibitory factor I-kB $\alpha$, induced by the I-kB kinase complex [230]. In wildtype mice, TG2 expression is increased during endotoxemia and, being the enzyme directly involved in the mechanisms of NF-kB activation through an I-kB kinase independent pathway, which is mediated by the polymerization of $\mathrm{I}-\mathrm{kB} \alpha$ [231], it may cause a continuous activation cycle in the inflammatory process, thus contributing to the development of sepsis pathogenesis. The increased survival of $\mathrm{TG}^{-/-}$mice was also reflected in a drastic reduction of organ injury, which is characterized by a limited infiltration of neutrophils, in the kidney and the peritoneum, and by a better homeostasis of the proinflammatory mediators and of mitochondrial functionality [228]. In keeping with this assumption, it has been shown that the TG2 inhibition switches off inflammation both in vitro and in vivo, in the homozygous F508del-CFTR mice model for cystic fibrosis (CF). CF is a monogenic disease caused by mutations in the $\mathrm{CF}$ transmembrane conductance regulator gene and characterized by chronic bacterial infections in the lungs and by inflammation. TG2 has been shown to be constitutively upregulated in CF and 
to play a key role in the onset of chronic inflammation [232, 233]. It has been proposed that the persistent TG2 activation observed relies on the action of the TG2-dependent SUMOylation of the protein inhibitor of activated STAT $\mathrm{y}$ and thus to inhibition of TG2 ubiquitination and proteasome degradation. This prevents peroxisome proliferator-activated receptor (PPAR) gamma and IkB $\alpha$ SUMOylation, triggering NF-kB activation and an uncontrolled inflammatory response [234]. These data suggested that TG2 might function as a link between oxidative stress and inflammation, by driving the decision as to whether a protein should undergo SUMO-mediated regulation or degradation. Targeting TG2-SUMO interactions may represent a new option in controling disease evolution in patients with $\mathrm{CF}$ and in other chronic inflammatory diseases. Indeed, the variety of TG2's protein substrates and of the biological functions it exerts inside the cell suggests the enzyme's involvement at different levels of the inflammation cascade (i.e., NF-kB activation, cytokine homeostasis, mitochondrial function). In this picture, the development of specific TG2 inhibitors could represent a novel approach in the treatment of the inflammatory process with important clinical implications.

\section{B. INTRACELLULAR PROTEIN INCLUSIONS-RELATED DISORDERS}

A number of severe human diseases are associated with the presence of noncorrectly folded proteins that exhibit decreased solubility under physiological conditions. These diseases result either from mutations, able to change the amino acid sequence of a protein, or from misfolding of wild-type proteins that cause the formation of nuclear and/or cytoplasmic aggregates of stainable substances known as inclusion bodies.

\section{Neurodegenerative Diseases}

Accumulation of misfolded proteins in proteinaceous inclusions is a prominent pathological feature common to many age-related neurodegenerative diseases, including $\mathrm{PD}, \mathrm{AD}, \mathrm{HD}$, and amyotrophic lateral sclerosis (ALS) [235].

$\mathrm{AD}$, the most common age-related neurodegenerative disorder, is associated with the selective damage of brain regions and neural circuits including, but not exclusively, neurons in the neo-cortex, hippocampus, and amygdala. Dysfunction and loss of neurons in these neural circuits result in impaired memory, thinking, and behavior. Two major hallmarks of AD pathology are extracellular neuritic senile plaques and intraneuronal 
neurofibrillary tangles. Senile plaques and neurofibrillary tangles are formed by abnormally polymerized proteins in the brain, and both these lesions are extremely insoluble structures. The purification and analysis of senile plaques demonstrated that they are comprised of fibrils of the amyloid $\beta$-protein $(A \beta)$. A $\beta$ is a 39-42 amino acid peptide derived from the proteolysis of a larger transmembrane glycoprotein, the amyloid precursor protein [236-238]. Neurofibrillary tangles are composed primarily of paired helical filaments (PHFs) [239, 240]; a major component of the PHFs is the hyperphosphorylated form of the microtubule-associated protein tau [241-243]. It has been hypothesized that TG2 may be involved in the pathogenesis of $\mathrm{AD}$ by facilitating the formation of one or both of these insoluble lesions. Biochemical and immuno-cytochemical assays have revealed TG2 expression in neurons of both normal and AD-affected elderly individuals [244, 245]. Miller and Anderton investigated the possible role of TG2 in the cross-linking of neurofilaments and extended the previous findings by demonstrating that all three neurofilaments polypeptides are TG2 substrates and can be cross-linked into insoluble, but nonfilamentous aggregates. Neurofibrillary tangles' major component is an abnormally phosphorylated form of the microtubule-associated protein tau but not neurofilament; therefore, it was hypothesized that the pathological aggregation of tau into insoluble neurofibrillary tangles may be enzymatically facilitated by TG2. Accordingly, several studies have demonstrated that tau is readily cross-linked by TG2 [244, 246, 247].

$\mathrm{HD}$ is a dominantly inherited disorder characterized by a progressive degeneration of motor neuron coupled to an impairment of coordination and with variable mental syndromes [191]. The disease's molecular basis relies on the expansion of the CAG tri-nucleotide repeat in the gene encoding for huntingtin (htt). This expansion leads to the presence of a stretch of polyglutamine in the expressed protein. In individuals not affected by HD, the number of CAG repeats varies from 6 to 35, whereas lengths of 40 and over invariably cause the onset of the pathology [248]; the longer is the repeat the more severe are the patient's clinical symptoms [249].

Several studies have proposed that HD might be caused in part by abnormal protein-protein interactions related to the elongated poly-glutamine stretch of huntingtin. The presence of both neuronal intranuclear and cytosolic inclusions, composed of mutant huntingtin, has been detected in brains of both HD patients and HD animal models [250,251], although it is not clear whether such inclusions are harmful or beneficial gent [252]. Nevertheless, 
they are likely to play a role in the onset and progression of the disease and a role for TG2 in their formation, growth and/or stabilization has been proposed [253]. It has also been hypothesized that one of mechanisms for htt aggregation is based on the action of TG2 on the expanded poly-glutamine repeats, which might act as excellent glutaminyl-donor substrates for the TG2-catalyzed cross-linking reaction [254]. On the other hand, the analysis of a mice model derived by crossing HD R6/1 transgenic mice with TG2 $2^{-/-}$ ones highlighted an increase in the formation of htt aggregates. The HD R6/1/TG2 ${ }^{-l-}$ mice showed a reduction of neuronal cell death coupled with a significant improvement in both locomotory performance and survival, as compared with the HD R6/1/TG2 ${ }^{+/+}$[92]. This suggests that the involvement of TG2 in the loss of neurons in HD is not related to the formation of htt aggregates.

Although TG2's role in the aggregate formation is yet to be fully established, it is clear that TG2 could contribute to the pathogenesis of HD through other mechanisms than the formation of aggregates. The interplay between TG2 and some mitochondrial functions could be one of the mechanisms involved in the pathogenesis of $\mathrm{HD}$, although supporting evidence for this hypothesis is still lacking. It remains the case that an impairment in the mitochondrial function, which has been proposed as one of the pathological mechanisms of HD, resulted in a significant increase of TGase activity in situ [255]. In addition, it has been shown that TG2 might act as a "sensitizer" towards apoptotic stimuli by modulating mitochondrial function [41]. This evidence is also supported by the fact that the $\mathrm{TG}^{-/-}$mice showed a defect in the activity of the mitochondrial respiratory complex I, this defect being partially compensated by an increase in the activity of complex II [151].

Recent studies have proved that autophagy plays a protective role towards the progression of $\mathrm{HD}$, being the fundamental mechanism for removing protein aggregates [256]. The hypothesis that autophagy might contribute to the pathogenesis of neurodegenerative diseases was initially supported by reports demonstrating that autophagosomes accumulate in the brains of these patients $[187,257]$. In addition, studies on mice with cerebellar degeneration, due to mutations in the glutamate receptor, suggested that autophagy might be a mechanism of nonapoptotic cell death [258]. In contrast, more recent studies provide compelling evidence that, at least in model organisms, autophagy might be a protection mechanism against various neurodegenerative diseases and that the accumulation of autophagosomes represents 
the activation of autophagy as a beneficial physiological response or, as in the case of $\mathrm{AD}$, the consequence of a defect in the maturation of autophagosomes. In this context, autophagy could be responsible not only for the clearance of spontaneously generated misfolded proteins and for routine protein turnover but it may also play an important role in the clearance of aggregate-prone mutant proteins often associated with neurodegenerative diseases. Normal protein turnover via proteasome requires the substrates to be unfolded in order to pass through the narrow pore of the proteasomal barrel. The bulk aggregates formed by poly-glutamine (poly-Q) expansion, as in HD; mutant $\alpha$-synuclein, as in familial PD; and different forms of tau, including mutations causing fronto-temporal dementia [257] result to be poor substrates for this degradation pathway and might be better targets for autophagic degradation.

The mechanism by which these proteins exert their cellular toxicity is still controversial, but it is generally believed that they are particularly toxic in oligomeric complexes and that higherorder protein aggregates may be formed as a last attempt to prevent toxicity, in the absence of a properly functioning quality-control system [259].

Autophagy has fundamental functions in cellular homeostasis and its modulation has been proposed as a therapeutic strategy for neurodegenerative diseases associated with aggregate formation, such as HD [187]. Considering that $\mathrm{TG} 2^{-/-}$mice showed an inhibition of the maturation of autophagolysosomes, the increased number of NII observed in the TG $2^{-1-} / \mathrm{HD}$ mice [92] is very likely explained by the inhibitory effect on autophagy progression caused by TG2 absence. Although the molecular mechanism(s) by which TG2 can regulate autophagy is not yet known, the most plausible hypothesis suggests a possible effect at the level of cytoskeleton. Since TG2 can post-translationally modify the major component of cytoskeleton such as tubulin, actin, and vimentin and so deeply influence its regulation $[8,59,209]$, future studies should verify this hypothesis as well as identifying other possible biochemical pathways by which the enzyme cross-linking activity regulates autophagy.

\section{Liver Steatohepatitis}

Mallory body (MB) inclusions are a characteristic feature of several liver disorders and share similarities with cytoplasmic inclusions observed in neural diseases and myopathies. MBs are composed mainly of keratins 8 and 
18 (K8/K18) and contain glutamine-lysine cross-links catalyzed by TG2. In a mouse model of MBs, the inhibition of TG2, achieved by the use of the specific inhibitor KCC009, causes a reduction of the 3,5-diethoxycarbonyl1,4-dihydrocollidine-induced liver enlargement, without affecting MB formation or the extent of the liver injury. The observed hepatomegaly is due to increased hepatocytes cell size rather than due to their proliferation [260]. Hence, once again, TG2 inhibition does not affect the MB formation, similar to what has been reported for the NII in the HD/TG2 ${ }^{-/-}$mice. However, in clear contrast with these results, the inhibition of MB formation has been observed in an experimental model based on the $\mathrm{TG} 2^{-/-}$mice. Further studies should clarify this controversial aspect of the problem.

It is important to note that a common feature of several liver disorders (including alcoholic and non-alcoholic steatohepatitis) is the accumulation of intra-cellular protein aggregates, which are known to be cleared by autophagy. It has been observed that rapamycin treatment decreased the number of inclusions significantly. Thus, TG2 inhibition associated with autophagy provides a potential cellular approach for the resorption of cytoplasmic inclusions.

Recently, it has been shown that autophagy is involved in the normal physiology of pancreatic $\beta$ cells and thus in the maintenance of the glucose homeostasis. Accordingly, Atg7 mutant mice develop impaired glucose tolerance and decreased serum insulin level [261]. Morphological analysis of autophagy-deficient $\beta$ cells in these mice revealed the accumulation of ubiquitinated protein aggregates that colocalize with p62. These features associate with mitochondrial swelling and vacuolar changes [262]. Given that $\mathrm{TG}^{-1-}$ mice develop a type II diabetes syndrome [202], it would be worth to investigate the involvement of TG2 and autophagy induction in the onset of this disease.

\section{Cardiac Diseases}

Constitutive autophagy plays an important role in the maintenance of cellular homeostasis in the heart, whereas unrestrained autophagic activity accentuates the maladaptive cardiac remodeling in response to stress (e.g., hypertension) and may contribute to heart failure [263]. Recent reports demonstrate that multiple forms of cardiovascular stress, including pressure overload, chronic ischemia, and infarction-reperfusion injury, lead to an increase of autophagy in cardiomyocytes [264-266]. In this regard, an accumulation of autophagosomes has been detected in biopsies of 
cardiac tissues belonging to patients suffering from these cardiac diseases, as well as in rodent models and isolated stressed cardiomyocytes [267, 268]. Since cardiac myocytes are terminally differentiated cells, the role of autophagy is essential for maintaining the homeostasis of the myocardium. Autophagy supplies nutrients for the synthesis of essential proteins during starvation and thus helps to extend cell survival. Under pathological settings, protein aggregation occurs in the heart in response to hemodynamic stress, putting pressure-overload heart disease in the category of proteinopathies [269]. Protein aggregation is the trigger of cardiomyocyte autophagy, which functions to attenuate aggregate/aggresome formation in the heart [270].

It has been recently shown that angiotensin II increases autophagosome formation, via the angiotensin II type 1 (AT1) receptor, and that, in neonatal cardiomyocytes, this response is constitutively antagonized by the coexpression of the angiotensin II type 2 (AT2) receptor [271, 272]. Interestingly, TG2 cross-links the carboxyl-terminal tail of the AT1 receptor and the so-formed receptor dimers display enhanced signaling as well as desensitization both in vitro and in vivo [273].

The heart consumes more energy per gram of tissue than any other organ in the body; thus the most common cardiac disorders (e.g., cardiac ischemia and heart failure) are characterized by a reduction in the availability of energy substrates, a factor that contributes to transient or sustained impairment of cardiac function. Furthermore, when cardiac stresses are sustained for long periods of time, myocytes remodel their cellular architecture (e.g., undergo elongation and hypertrophy) in order to adapt to stress. It has been hypothesized that, when the heart is under stress, its need for more energy and for cellular remodeling could be met, at least partly, by via activation of the autophagy pathway. In keeping with this hypothesis, cardiac-specific deficiency of Atg5, early in cardiogenesis, results in no phenotypic abnormality under basal conditions; instead, after treatment with pressure overload or $\alpha$ adrenergic stress, severe cardiac dysfunction becomes evident. Interestingly, the stimulation of the $\alpha(1)$-adrenoreceptor in cardiac myocytes prompts the appearance of a hyper-trophic phenotype [269].

Ablation of TG2 in mice has been shown to cause an increased vulnerability of cardiomyocytes to ischemia/reperfusion injury. This effect is associated with a decreased capacity of $\mathrm{TG} 2^{-1-}$ mice to synthesize ATP, due to both a reduced activity of mitochondrial complex I and to defects in the functions of the ATP/ADP transporter [40, 151, 152, 153]. Taking into account the role played by TG2 in the autophagosome formation, 
it is tempting to hypothesize that the vulnerability displayed by the cardiac muscle of the $\mathrm{TG}^{-/-}$mice could be due not only to their congenital mitochondrial defects, but also to an impaired autophagic response to cellular stress [274].

\section{CONCLUSIONS}

Despite the extensive research carried out to date, the comprehension of the physiological role played by TG2 remains largely unknown as does the significance of the post-translational modifications of its protein substrates. This review offers further compelling evidence that under physiological and pathological circumstances, the enzyme is mainly involved in the regulation of cell death. Accordingly, it seems clear that under physiological settings the up-regulation and the activation of TG2 are associated with the induction of apoptosis. On the other hand, in pathological conditions, such as in cancer cells, the enzyme may act both as a pro-survival and a pro-death factor, depending upon the cell type and/or its subcellular localization (Figure 3). In addition, a deregulation of TG2 has been proposed as playing a major role in various diseases, including cardiomyopathy, hepatitis, diabetes, and neurodegenerative disorders. A common feature of all these pathologies relies on the accumulation of misfolded proteins in proteinaceous inclusions. It has become increasingly evident that, in all these disease, the affected cell activates autophagy in order to eliminate these large protein aggregates. It is worth noting that several TG2 candidate protein substrates have been shown to be enriched on the membrane of the autophagosomes (Table 3). These findings, taken together with the blockade of the autophagosome maturation observed in the TG2 ${ }^{-l-}$ mice, support TG2's involvement in the final process of the autolysosomes maturation in multiple ways. Future studies should address the different controversial points in order to establish whether TG2 could indeed be used as a target for treatment of the abovementioned degenerative diseases.

\section{ACKNOWLEDGMENTS}

This work was partly funded by grants from European Community "APO-SYS" and "TRAKS;" Ricerca corrente e finalizzata del "Ministero della Salute." The financial support from Italian Telethon Foundation, A.I.R.C. (grants to M.P.), Compagnia di San Paolo and CHDI Foundation Inc. (USA) is gratefully acknowledged. 


\section{REFERENCES}

1. Folk, J. E. and Finlayson, J. S. (1977) The epsilon-(gamma-glutamyl)lysine crosslink and the catalytic role of transglutaminases, Adv. Protein Chem. 31, 1.

2. Lorand, L. and Conrad, S. M. (1984) Transglutaminases, Mol. Cell. Biochem. 58, 9.

3. Grenard, P., Bates, M. K., and Aeschlimann, D. (2001) Evolution of transglutaminase genes: identification of a transglutaminase gene cluster on human chromosome $15 \mathrm{q} 15$. Structure of the gene encoding transglutaminase $X$ and a novel gene family member, transglutaminase Z, J. Biol. Chem. 276, 33066.

4. Makarova, K. S., Aravind, L., and Koonin, E. V. (1999) A superfamily of archaeal, bacterial, and eukaryotic proteins homologous to animal transglutaminases, Protein Sci. $8,1714$.

5. Mosher, D. F., Schad, P. E., and Kleinman, H. K. (1979) Inhibition of blood coagulation factor XIIIa-mediated cross-linking between fibronectin and collagen by polyamines, J. Supramol. Struct. 11, 227.

6. Kim, S. Y., Kim, I. G., Chung, S. I., and Steinert, P. M. (1994) The structure of the transglutaminase 1 enzyme. Deletion cloning reveals domains that regulate its specific activity and substrate specificity, J. Biol. Chem. 269, 27979.

7. Rice, R. H. and Green, H. (1978) Relation of protein synthesis and transglutaminase activity to formation of the cross-linked envelope during terminal differentiation of the cultured human epidermal keratinocyte, J. Cell Biol. 76, 705.

8. Fesus, L. and Piacentini, M. (2002) Transglutaminase 2: an enigmatic enzyme with diverse functions, Trends Biochem. Sci. 27, 534.

9. Lorand, L. and Graham, R. M. (2003) Transglutaminases: crosslinking enzymes with pleiotropic functions, Nat. Rev. Mol. Cell Biol. 4, 140.

10. Lee, J. H., Jang, S. I., Yang, J. M., Markova, N. G., and Steinert, P. M. (1996) The proximal promoter of the human transglutaminase 3 gene. Stratified squamous epithelialspecific expression in cultured cells is mediated by binding of $\mathrm{Sp} 1$ and ets transcription factors to a proximal promoter element, J. Biol. Chem. 271, 4561.

11. Dubbink, H. J., de Waal, L., van Haperen, R., Verkaik, N. S., Trapman, J., and Romijn, J. C. (1998) The human prostate-specific transglutaminase gene (TGM4): genomic organization, tissue-specific expression, and promoter characterization, Genomics 51, 434.

12. Candi, E., Oddi, S., Terrinoni, A., Paradisi, A., Ranalli, M., Finazzi-Agro, A., and Melino, G. (2001) Transglutaminase 5 cross-links loricrin, involucrin, and small proline-rich proteins in vitro, J. Biol. Chem. 276, 35014.

13. Lee, C. J., Do, B. R., Lee, J. M., Song, K. W., Kang, J. S., and Park, M. H. (2003) Differential expression of tissue transglutaminase protein in mouse ovarian follicle, In Vivo 17, 235.

14. Polakowska, R. R., Graf, B. A., Falciano, V., and LaCelle, P. (1999) Transcription regulatory elements of the first intron control human transglutaminase type I gene expression in epidermal keratinocytes, J. Cell Biochem. 73, 355.

15. Im, M. J. and Graham, R. M. (1990) A novel guanine nucleotide-binding protein coupled to the alpha 1-adrenergic receptor. I. Identification by photolabeling or membrane and ternary complex preparation, J. Biol. Chem. 265, 18944. 
16. Im, M. J., Riek, R. P., and Graham, R. M. (1990) A novel guanine nucleotide-binding protein coupled to the alpha 1-adrenergic receptor. II. Purification, characterization, and reconstitution, J. Biol. Chem. 265, 18952.

17. Spina, A. M., Esposito, C., Pagano, M., Chiosi, E., Mariniello, L., Cozzolino, A., Porta, R., and Illiano, G. (1999) GTPase and transglutaminase are associated in the secretion of the rat anterior prostate, Biochem. Biophys. Res. Commun. 260, 351.

18. Candi, E., Paradisi, A., Terrinoni, A., Pietroni, V., Oddi, S., Cadot, B., Jogini, V., Meiyappan, M., Clardy, J., Finazzi-Agro, A., and Melino, G. (2004) Transglutaminase 5 is regulated by guanine-adenine nucleotides, Biochem. J. 381, 313 .

19. Liu, S., Cerione, R. A., and Clardy, J. (2002) Structural basis for the guanine nucleotidebinding activity of tissue transglutaminase and its regulation of transamidation activity, Proc. Natl. Acad. Sci. U.S.A. 99, 2743.

20. Nakaoka, H., Perez, D. M., Baek, K. J., Das, T., Husain, A., Misono, K., Im, M. J., and Graham, R. M. (1994) Gh: a GTP-binding protein with transglutaminase activity and receptor signaling function, Science 264, 1593.

21. Mishra, S. and Murphy, L. J. (2004) Tissue transglutaminase has intrinsic kinase activity: identification of transglutaminase 2 as an insulin-like growth factor-binding protein-3 kinase, J. Biol. Chem. 279, 23863.

22. Mishra, S. and Murphy, L. J. (2006) The p53 oncoprotein is a substrate for tissue transglutaminase kinase activity, Biochem. Biophys. Res. Commun. 339, 726.

23. Mishra, S., Saleh, A., Espino, P. S., Davie, J. R., and Murphy, L. J. (2006) Phosphorylation of histones by tissue transglutaminase, J. Biol. Chem. 281, 5532.

24. Hasegawa, G., Suwa, M., Ichikawa, Y., Ohtsuka, T., Kumagai, S., Kikuchi, M., Sato, Y., and Saito, Y. (2003) A novel function of tissue-type transglutaminase: protein disulphide isomerase, Biochem. J. 373, 793.

25. Mastroberardino, P. G., Farrace, M. G., Viti, I., Pavone, F., Fimia, G. M., Melino, G., Rodolfo, C., and Piacentini, M. (2006) "Tissue" transglutaminase contributes to the formation of disulphide bridges in proteins of mitochondrial respiratory complexes, Biochim. Biophys. Acta 1757, 1357.

26. Ueki, S., Takagi, J., and Saito, Y. (1996) Dual functions of transglutaminase in novel cell adhesion, J. Cell Sci. 109(Pt 11), 2727.

27. Lorand, L. (1988) Transglutaminase-mediated cross-linking of proteins and cell ageing: the erythrocyte and lens models, Adv. Exp. Med. Biol. 231, 79.

28. Kim, S. Y., Jeitner, T. M., and Steinert, P. M. (2002) Transglutaminases in disease, Neurochem. Int. 40, 85.

29. D'Amato, M., Iannicola, C., Monteriu, G., and Piacentini, M. (1999), Mapping and sequencing of the murine 'tissue' transglutaminase (Tgm2) gene: absence of mutations in MRLlpr/lpr mice, Cell Death Differ. 6, 216.

30. Gentile, V., Davies, P. J., and Baldini, A. (1994), The human tissue transglutaminase gene maps on chromosome 20q12 by in situ fluorescence hybridization, Genomics 20, 295.

31. Fraij, B. M. and Gonzales, R. A. (1997), Organization and structure of the human tissue transglutaminase gene, Biochim. Biophys. Acta 1354, 65. 
32. Gentile, V., Saydak, M., Chiocca, E. A., Akande, O., Birckbichler, P. J., Lee, K. N., Stein, J. P., and Davies, P. J. (1991) Isolation and characterization of cDNA clones to mouse macrophage and human endothelial cell tissue transglutaminases, J. Biol. Chem. $266,478$.

33. Fesus, L. and Arato, G. (1986), Quantitation of tissue transglutaminase by a sandwich ELISA system, J. Immunol. Methods 94, 131.

34. Thomazy, V. and Fesus, L. (1989) Differential expression of tissue transglutaminase in human cells. An immunohistochemical study, Cell Tissue Res. 255, 215.

35. Di Venere, A., Rossi, A., De Matteis, F., Rosato, N., Agro, A. F., and Mei, G. (2000) Opposite effects of $\mathrm{Ca}(2+)$ and GTP binding on tissue transglutaminase tertiary structure, J. Biol. Chem. 275, 3915.

36. Pedersen, L. C., Yee, V. C., Bishop, P. D., Le Trong, I., Teller, D. C., and Stenkamp, R. E. (1994) Transglutaminase factor XIII uses proteinase-like catalytic triad to crosslink macromolecules, Protein Sci. 3, 1131.

37. Yee, V. C., Pedersen, L. C., Le Trong, I., Bishop, P. D., Stenkamp, R. E., and Teller, D. C. (1994) Three-dimensional structure of a transglutaminase: human blood coagulation factor XIII, Proc. Natl. Acad. Sci. U.S.A. 91, 7296.

38. Noguchi, K., Ishikawa, K., Yokoyama, K., Ohtsuka, T., Nio, N., and Suzuki, E. (2001) Crystal structure of red sea bream transglutaminase, J. Biol. Chem. 276, 12055.

39. Singh, U. S., Erickson, J. W., and Cerione, R. A. (1995) Identification and biochemical characterization of an 80 kilodalton GTP-binding/transglutaminase from rabbit liver nuclei, Biochemistry 34, 15863.

40. Malorni, W., Farrace, M. G., Matarrese, P., Tinari, A., Ciarlo, L., Mousavi-Shafaei, P., D’Eletto, M., Di Giacomo, G., Melino, G., Palmieri, L., Rodolfo, C., and Piacentini, M. (2009) The adenine nucleotide translocator 1 acts as a type 2 transglutaminase substrate: implications for mitochondrial-dependent apoptosis, Cell Death Differ. 16, 1480.

41. Piacentini, M., Farrace, M. G., Piredda, L., Matarrese, P., Ciccosanti, F., Falasca, L., Rodolfo, C., Giammarioli, A. M., Verderio, E., Griffin, M., and Malorni, W. (2002), Transglutaminase overexpression sensitizes neuronal cell lines to apoptosis by increasing mitochondrial membrane potential and cellular oxidative stress, J. Neurochem. 81, 1061 .

42. Gaudry, C. A., Verderio, E., Aeschlimann, D., Cox, A., Smith, C., and Griffin, M. (1999) Cell surface localization of tissue transglutaminase is dependent on a fibronectin-binding site in its N-terminal beta-sandwich domain, J. Biol. Chem. 274, 30707.

43. Gaudry, C. A., Verderio, E., Jones, R. A., Smith, C., and Griffin, M. (1999) Tissue transglutaminase is an important player at the surface of human endothelial cells: evidence for its externalization and its colocalization with the beta(1) integrin, Exp. Cell Res. 252, 104.

44. Stevens, H. Y., Reeve, J., and Noble, B. S. (2000) Bcl-2, tissue transglutaminase and p53 protein expression in the apoptotic cascade in ribs of premature infants, J. Anat. 196(Pt 2), 181.

45. Radek, J. T., Jeong, J. M., Murthy, S. N., Ingham, K. C., and Lorand, L. (1993) Affinity of human erythrocyte transglutaminase for a $42-\mathrm{kDa}$ gelatin-binding fragment of human plasma fibronectin, Proc. Natl. Acad. Sci. U.S.A. 90, 3152. 
46. Akimov, S. S., Krylov, D., Fleischman, L. F., and Belkin, A. M. (2000) Tissue transglutaminase is an integrin-binding adhesion coreceptor for fibronectin, J. Cell Biol. 148, 825.

47. Telci, D., Wang, Z., Li, X., Verderio, E. A., Humphries, M. J., Baccarini, M., Basaga, H., and Griffin, M. (2008) Fibronectin-tissue transglutaminase matrix rescues RGDimpaired cell adhesion through syndecan-4 and beta1 integrin co-signaling, J. Biol. Chem. 283, 20937.

48. Xu, L., Begum, S., Hearn, J. D., and Hynes, R. O. (2006) GPR56, an atypical G proteincoupled receptor, binds tissue transglutaminase, TG2, and inhibits melanoma tumor growth and metastasis, Proc. Natl. Acad. Sci. U.S.A. 103, 9023.

49. Vezza, R., Habib, A., and FitzGerald, G. A. (1999) Differential signaling by the thromboxane receptor isoforms via the novel GTP-binding protein, Gh, J. Biol. Chem. 274, 12774.

50. Park, E. S., Won, J. H., Han, K. J., Suh, P. G., Ryu, S. H., Lee, H. S., Yun, H. Y., Kwon, N. S., and Baek, K. J. (1998) Phospholipase C-delta1 and oxytocin receptor signalling: evidence of its role as an effector, Biochem. J. 331(Pt 1), 283.

51. Rodolfo, C., Mormone, E., Matarrese, P., Ciccosanti, F., Farrace, M. G., Garofano, E., Piredda, L., Fimia, G. M., Malorni, W., and Piacentini, M. (2004) Tissue transglutaminase is a multifunctional BH3-only protein, J. Biol. Chem. 279, 54783.

52. Piacentini, M., Rodolfo, C., Farrace, M. G., and Autuori, F. (2000) "Tissue" transglutaminase in animal development, Int. J. Dev. Biol. 44, 655.

53. Szegezdi, E., Szondy, Z., Nagy, L., Nemes, Z., Friis, R. R., Davies, P. J., and Fesus, L. (2000) Apoptosis-linked in vivo regulation of the tissue transglutaminase gene promoter, Cell Death Differ. 7, 1225.

54. Iismaa, S. E., Chung, L., Wu, M. J., Teller, D. C., Yee, V. C., and Graham, R. M. (1997) The core domain of the tissue transglutaminase Gh hydrolyzes GTP and ATP, Biochemistry 36, 11655.

55. Iismaa, S. E., Wu, M. J., Nanda, N., Church, W. B., and Graham, R. M. (2000) GTP binding and signaling by $\mathrm{Gh} /$ transglutaminase II involves distinct residues in a unique GTP-binding pocket, J. Biol. Chem. 275, 18259.

56. Murthy, S. N., Lomasney, J. W., Mak, E. C., and Lorand, L. (1999) Interactions of G(h)/transglutaminase with phospholipase Cdelta1 and with GTP, Proc. Natl. Acad. Sci. U.S.A. 96, 11815 .

57. Lai, T. S., Bielawska, A., Peoples, K. A., Hannun, Y. A., and Greenberg, C. S. (1997) Sphingosylphosphocholine reduces the calcium ion requirement for activating tissue transglutaminase, J. Biol. Chem. 272, 16295.

58. Lai, T. S., Hausladen, A., Slaughter, T. F., Eu, J. P., Stamler, J. S., and Greenberg, C. S. (2001) Calcium regulates S-nitrosylation, denitrosylation, and activity of tissue transglutaminase, Biochemistry 40, 4904.

59. Singh, U. S., Kunar, M. T., Kao, Y. L., and Baker, K. M. (2001), Role of transglutaminase II in retinoic acid-induced activation of RhoA-associated kinase-2, Embo. J. 20, 2413.

60. Singh, U. S., Pan, J., Kao, Y. L., Joshi, S., Young, K. L., and Baker, K. M. (2003), Tissue transglutaminase mediates activation of RhoA and MAP kinase pathways during 
retinoic acid-induced neuronal differentiation of SH-SY5Y cells, J. Biol. Chem. 278, 391.

61. Murthy, S. N., Wilson, J. H., Lukas, T. J., Kuret, J., and Lorand, L. (1998) Crosslinking sites of the human tau protein, probed by reactions with human transglutaminase, J. Neurochem. 71, 2607.

62. Piredda, L., Farrace, M. G., Lo Bello, M., Malorni, W., Melino, G., Petruzzelli, R., and Piacentini, M. (1999) Identification of 'tissue' transglutaminase binding proteins in neural cells committed to apoptosis, Faseb. J. 13, 355.

63. Peng, X., Zhang, Y., Zhang, H., Graner, S., Williams, J. F., Levitt, M. L., and Lokshin, A. (1999) Interaction of tissue transglutaminase with nuclear transport protein importinalpha3, FEBS Lett. 446, 35.

64. Ballestar, E., Abad, C., and Franco, L. (1996) Core histones are glutaminyl substrates for tissue transglutaminase, J. Biol. Chem. 271, 18817.

65. Ballestar, E., Boix-Chornet, M., and Franco, L. (2001) Conformational changes in the nucleosome followed by the selective accessibility of histone glutamines in the transglutaminase reaction: effects of ionic strength, Biochemistry 40, 1922.

66. Oliverio, S., Amendola, A., Di Sano, F., Farrace, M. G., Fesus, L., Nemes, Z., Piredda, L., Spinedi, A., and Piacentini, M. (1997) Tissue transglutaminase-dependent posttranslational modification of the retinoblastoma gene product in promonocytic cells undergoing apoptosis, Mol. Cell Biol. 17, 6040.

67. Fesus, L., Thomazy, V., Autuori, F., Ceru, M. P., Tarcsa, E., and Piacentini, M. (1989) Apoptotic hepatocytes become insoluble in detergents and chaotropic agents as a result of transglutaminase action, FEBS Lett. 245, 150.

68. Fesus, L., Thomazy, V., and Falus, A. (1987) Induction and activation of tissue transglutaminase during programmed cell death, FEBS Lett. 224, 104.

69. Oliverio, S., Amendola, A., Rodolfo, C., Spinedi, A., and Piacentini, M. (1999) Inhibition of "tissue" transglutaminase increases cell survival by preventing apoptosis, J. Biol. Chem. 274, 34123.

70. Tatsukawa, H., Fukaya, Y., Frampton, G., Martinez-Fuentes, A., Suzuki, K., Kuo, T. F., Nagatsuma, K., Shimokado, K., Okuno, M., Wu, J., Iismaa, S., Matsuura, T., Tsukamoto, H., Zern, M. A., Graham, R. M., and Kojima, S. (2009) Role of transglutaminase 2 in liver injury via cross-linking and silencing of transcription factor Sp1, Gastroenterology 136, 1783.

71. Polakowska, R. R., Piacentini, M., Bartlett, R., Goldsmith, L. A., and Haake, A. R. (1994) Apoptosis in human skin development: morphogenesis, periderm, and stem cells, Dev. Dyn. 199, 176.

72. Szondy, Z., Molnar, P., Nemes, Z., Boyiadzis, M., Kedei, N., Toth, R., and Fesus, L. (1997) Differential expression of tissue transglutaminase during in vivo apoptosis of thymocytes induced via distinct signalling pathways, FEBS Lett. 404, 307.

73. Szondy, Z., Reichert, U., Bernardon, J. M., Michel, S., Toth, R., Ancian, P., Ajzner, E., and Fesus, L. (1997) Induction of apoptosis by retinoids and retinoic acid receptor gamma-selective compounds in mouse thymocytes through a novel apoptosis pathway, Mol. Pharmacol. 51, 972. 
74. Nagy, L., Thomazy, V. A., and Davies, P. J. (1998) A transgenic mouse model for the study of apoptosis during limb development, Cell Death Differ. 5, 126.

75. Thomazy, V. A. and Davies, P. J. (1999) Expression of tissue transglutaminase in the developing chicken limb is associated both with apoptosis and endochondral ossification, Cell Death Differ. 6, 146.

76. Sarang, Z., Madi, A., Koy, C., Varga, S., Glocker, M. O., Ucker, D. S., Kuchay, S., Chishti, A. H., Melino, G., Fesus, L., and Szondy, Z. (2007) Tissue transglutaminase (TG2) facilitates phosphatidylserine exposure and calpain activity in calcium-induced death of erythrocytes, Cell Death Differ. 14, 1842.

77. Nemes, Z., Jr., Friis, R. R., Aeschlimann, D., Saurer, S., Paulsson, M., and Fesus, L. (1996) Expression and activation of tissue transglutaminase in apoptotic cells of involuting rodent mammary tissue, Eur. J. Cell Biol. 70, 125.

78. Ruan, Q., Quintanilla, R. A., and Johnson, G. V. (2007) Type 2 transglutaminase differentially modulates striatal cell death in the presence of wild type or mutant huntingtin, J. Neurochem. 102, 25.

79. Rebe, C., Raveneau, M., Chevriaux, A., Lakomy, D., Sberna, A. L., Costa, A., Bessede, G., Athias, A., Steinmetz, E., Lobaccaro, J. M., Alves, G., Menicacci, A., Vachenc, S., Solary, E., Gambert, P., and Masson, D. (2009) Induction of transglutaminase 2 by a liver $\mathrm{X}$ receptor/retinoic acid receptor alpha pathway increases the clearance of apoptotic cells by human macrophages, Circ. Res. 105, 393.

80. Ou, H., Haendeler, J., Aebly, M. R., Kelly, L. A., Cholewa, B. C., Koike, G., KwitekBlack, A., Jacob, H. J., Berk, B. C., and Miano, J. M. (2000) Retinoic acid-induced tissue transglutaminase and apoptosis in vascular smooth muscle cells, Circ. Res. 87, 881.

81. Gorza, L., Menabo, R., Di Lisa, F., and Vitadello, M. (1997) Troponin T cross-linking in human apoptotic cardiomyocytes, Am. J. Pathol. 150, 2087.

82. Gorza, L., Menabo, R., Vitadello, M., Bergamini, C. M., and Di Lisa, F. (1996) Cardiomyocyte troponin $\mathrm{T}$ immunoreactivity is modified by cross-linking resulting from intracellular calcium overload, Circulation 93, 1896.

83. Assisi, L., Autuori, F., Botte, V., Farrace, M. G., and Piacentini, M. (1999) Hormonal control of "tissue" transglutaminase induction during programmed cell death in frog liver, Exp. Cell Res. 247, 339.

84. Lin, X. R., Wilkinson, D. I., and Farber, E. M. (1998) Camptothecin induces differentiation, tissue transglutaminase and apoptosis in cultured keratinocytes, Exp. Dermatol. 7,179 .

85. Zhang, S. R., Li, S. H., Abler, A., Fu, J., Tso, M. O., and Lam, T. T. (1996) Tissue transglutaminase in apoptosis of photoreceptor cells in rat retina, Invest. Ophthalmol. Vis. Sci. 37, 1793.

86. Dini, L., Falasca, L., Lentini, A., Mattioli, P., Piacentini, M., Piredda, L., and Autuori, F. (1993) Galactose-specific receptor modulation related to the onset of apoptosis in rat liver, Eur. J. Cell Biol. 61, 329.

87. Fesus, L., Tarcsa, E., Kedei, N., Autuori, F., and Piacentini, M. (1991) Degradation of cells dying by apoptosis leads to accumulation of epsilon(gamma-glutamyl)lysine isodipeptide in culture fluid and blood, FEBS Lett. 284, 109. 
88. Amendola, A., Gougeon, M. L., Poccia, F., Bondurand, A., Fesus, L., and Piacentini, M. (1996) Induction of "tissue" transglutaminase in HIV pathogenesis: evidence for high rate of apoptosis of CD4+ T lymphocytes and accessory cells in lymphoid tissues, Proc. Natl. Acad. Sci. U.S.A. 93, 11057.

89. Nardacci, R., Antinori, A., Larocca, L. M., Arena, V., Amendola, A., Perfettini, J. L., Kroemer, G., and Piacentini, M. (2005) Characterization of cell death pathways in human immunodeficiency virus-associated encephalitis, Am. J. Pathol. 167, 695.

90. Fujita, K., Kato, T., Shibayama, K., Imada, H., Yamauchi, M., Yoshimoto, N., Miyachi, E., and Nagata, Y. (2006) Protective effect against 17beta-estradiol on neuronal apoptosis in hippocampus tissue following transient ischemia/recirculation in mongolian gerbils via down-regulation of tissue transglutaminase activity, Neurochem. Res. 31, 1059.

91. Hwang, I. K., Yoo, K. Y., Yi, S. S., Kim, I. Y., Hwang, H. S., Lee, K. Y., Choi, S. M., Lee, I. S., Yoon, Y. S., Kim, S. Y., Won, M. H., and Seong, J. K. (2009) Expression of tissue-type transglutaminase (tTG) and the effect of tTG inhibitor on the hippocampal CA1 region after transient ischemia in gerbils, Brain Res. 1263, 134.

92. Mastroberardino, P. G., Iannicola, C., Nardacci, R., Bernassola, F., De Laurenzi, V., Melino, G., Moreno, S., Pavone, F., Oliverio, S., Fesus, L., and Piacentini, M. (2002) 'Tissue' transglutaminase ablation reduces neuronal death and prolongs survival in a mouse model of Huntington's disease, Cell Death Differ. 9, 873.

93. Sarnelli, G., De Giorgio, R., Gentile, F., Cali, G., Grandone, I., Rocco, A., Cosenza, V., Cuomo, R., and D’Argenio, G. (2009) Myenteric neuronal loss in rats with experimental colitis: role of tissue transglutaminase-induced apoptosis, Dig. Liver Dis. 41, 185.

94. Nemes, Z., Petrovski, G., Aerts, M., Sergeant, K., Devreese, B., and Fesus, L. (2009) Transglutaminase-mediated intramolecular cross-linking of membrane-bound alphasynuclein promotes amyloid formation in Lewy bodies, J. Biol. Chem. 284, 27252.

95. Griffin, M. and Verderio, E. (2000) Tissue transglutaminase in cell death, Symp. Soc. Exp. Biol. 52, 223.

96. Kroemer, G., El-Deiry, W. S., Golstein, P., Peter, M. E., Vaux, D., Vandenabeele, P., Zhivotovsky, B., Blagosklonny, M. V., Malorni, W., Knight, R. A., Piacentini, M., Nagata, S., and Melino, G. (2005) Classification of cell death: recommendations of the Nomenclature Committee on Cell Death, Cell Death Differ. 12(Suppl 2), 1463.

97. Krysko, D. V., D'Herde, K., and Vandenabeele, P. (2006) Clearance of apoptotic and necrotic cells and its immunological consequences, Apoptosis 11, 1709.

98. Piacentini, M. (1999) Apoptosis and autoimmunity: two sides to the coin, Cell Death Differ: 6, 1.

99. Kerr, J. F., Wyllie, A. H., and Currie, A. R. (1972) Apoptosis: a basic biological phenomenon with wide-ranging implications in tissue kinetics, Br. J. Cancer 26, 239.

100. Kroemer, G. and Reed, J. C. (2000) Mitochondrial control of cell death, Nat. Med. 6, 513.

101. Enari, M., Sakahira, H., Yokoyama, H., Okawa, K., Iwamatsu, A., and Nagata, S. (1998) A caspase-activated DNase that degrades DNA during apoptosis, and its inhibitor ICAD, Nature 391, 43.

102. De Duve, C. (1966) The significance of lysosomes in pathology and medicine, Proc. Inst. Med. Chic. 26, 73. 
103. De Duve, C. and Wattiaux, R. (1966) Functions of lysosomes, Annu. Rev. Physiol. 28, 435.

104. Maiuri, M. C., Zalckvar, E., Kimchi, A., and Kroemer, G. (2007) Self-eating and selfkilling: crosstalk between autophagy and apoptosis, Nat. Rev. Mol. Cell Biol. 8, 741.

105. Huang, J. and Klionsky, D. J. (2007) Autophagy and human disease, Cell Cycle 6, 1837.

106. Hotchkiss, R. S., Strasser, A., McDunn, J. E., and Swanson, P. E. (2009) Cell death, N. Engl. J. Med. 361, 1570.

107. Vanlangenakker, N., Vanden Berghe, T., Krysko, D. V., Festjens, N., and Vandenabeele, P. (2008) Molecular mechanisms and pathophysiology of necrotic cell death, Curr. Mol. Med. 8, 207.

108. Zong, W. X. and Thompson, C. B. (2006) Necrotic death as a cell fate, Genes Dev. $20,1$.

109. Galluzzi, L., Maiuri, M. C., Vitale, I., Zischka, H., Castedo, M., Zitvogel, L., and Kroemer, G. (2007) Cell death modalities: classification and pathophysiological implications, Cell Death Differ. 14, 1237.

110. Boya, P., Gonzalez-Polo, R. A., Casares, N., Perfettini, J. L., Dessen, P., Larochette, N., Metivier, D., Meley, D., Souquere, S., Yoshimori, T., Pierron, G., Codogno, P., and Kroemer, G. (2005) Inhibition of macroautophagy triggers apoptosis, Mol. Cell Biol. 25,1025 .

111. Gonzalez-Polo, R. A., Boya, P., Pauleau, A. L., Jalil, A., Larochette, N., Souquere, S., Eskelinen, E. L., Pierron, G., Saftig, P., and Kroemer, G. (2005) The apoptosis/autophagy paradox: autophagic vacuolization before apoptotic death, J. Cell Sci. 118, 3091.

112. Vandenabeele, P., Vanden Berghe, T., and Festjens, N. (2006) Caspase inhibitors promote alternative cell death pathways, Sci. STKE 2006, pe44.

113. Grabarek, J., Ardelt, B., Kunicki, J., and Darzynkiewicz, Z. (2002) Detection of in situ activation of transglutaminase during apoptosis: correlation with the cell cycle phase by multiparameter flow and laser scanning cytometry, Cytometry 49, 83.

114. Robitaille, K., Daviau, A., Tucholski, J., Johnson, G. V., Rancourt, C., and Blouin, R. (2004) Tissue transglutaminase triggers oligomerization and activation of dual leucine zipper-bearing kinase in calphostin C-treated cells to facilitate apoptosis, Cell Death Differ. 11, 542 .

115. Hwang, J. Y., Mangala, L. S., Fok, J. Y., Lin, Y. G., Merritt, W. M., Spannuth, W. A., Nick, A. M., Fiterman, D. J., Vivas-Mejia, P. E., Deavers, M. T., Coleman, R. L., LopezBerestein, G., Mehta, K., and Sood, A. K. (2008) Clinical and biological significance of tissue transglutaminase in ovarian carcinoma, Cancer Res. 68, 5849.

116. Shao, M., Cao, L., Shen, C., Satpathy, M., Chelladurai, B., Bigsby, R. M., Nakshatri, H., and Matei, D. (2009) Epithelial-to-mesenchymal transition and ovarian tumor progression induced by tissue transglutaminase, Cancer Res. 69, 9192.

117. Caraglia, M., Marra, M., Giuberti, G., D’Alessandro, A. M., Beninati, S., Lentini, A., Pepe, S., Boccellino, M., and Abbruzzese, A. (2002) Theophylline-induced apoptosis is paralleled by protein kinase A-dependent tissue transglutaminase activation in cancer cells, J. Biochem. (Tokyo) 132, 45.

118. Jang, J. H., Park, J. S., Lee, T. J., and Kwon, T. K. (2009) Transglutaminase 2 expression levels regulate sensitivity to cystamine plus TRAIL-mediated apoptosis, Cancer Lett. 287, 224. 
119. Fok, J. Y. and Mehta, K. (2007) Tissue transglutaminase induces the release of apoptosis inducing factor and results in apoptotic death of pancreatic cancer cells, Apoptosis 12, 1455 .

120. Cao, L., Petrusca, D. N., Satpathy, M., Nakshatri, H., Petrache, I., and Matei, D. (2008) Tissue transglutaminase protects epithelial ovarian cancer cells from cisplatin-induced apoptosis by promoting cell survival signaling, Carcinogenesis 29, 1893.

121. Joseph, B., Lefebvre, O., Mereau-Richard, C., Danze, P. M., Belin-Plancot, M. T., and Formstecher, P. (1998) Evidence for the involvement of both retinoic acid receptor- and retinoic $\mathrm{X}$ receptor-dependent signaling pathways in the induction of tissue transglutaminase and apoptosis in the human myeloma cell line RPMI 8226, Blood 91, 2423.

122. Lefebvre, O., Wouters, D., Mereau-Richard, C., Facon, T., Zandecki, M., Formstecher, P., and Belin, M. T. (1999) Induction of apoptosis by all-trans retinoic acid in the human myeloma cell line RPMI 8226 and negative regulation of some of its typical morphological features by dexamethasone, Cell Death Differ. 6, 433.

123. Yuan, L., Behdad, A., Siegel, M., Khosla, C., Higashikubo, R., and Rich, K. M. (2008) Tissue transgluaminase 2 expression in meningiomas, J. Neurooncol. 90, 125.

124. Yuan, L., Choi, K., Khosla, C., Zheng, X., Higashikubo, R., Chicoine, M. R., and Rich, K. M. (2005) Tissue transglutaminase 2 inhibition promotes cell death and chemosensitivity in glioblastomas, Mol. Cancer Ther. 4, 1293.

125. Esposito, C., Marra, M., Giuberti, G., D’Alessandro, A. M., Porta, R., Cozzolino, A., Caraglia, M., and Abbruzzese, A. (2003) Ubiquitination of tissue transglutaminase is modulated by interferon alpha in human lung cancer cells, Biochem. J. 370, 205.

126. Verma, A., Guha, S., Diagaradjane, P., Kunnumakkara, A. B., Sanguino, A. M., LopezBerestein, G., Sood, A. K., Aggarwal, B. B., Krishnan, S., Gelovani, J. G., and Mehta, K. (2008) Therapeutic significance of elevated tissue transglutaminase expression in pancreatic cancer, Clin. Cancer Res. 14, 2476.

127. Verma, A., Guha, S., Wang, H., Fok, J. Y., Koul, D., Abbruzzese, J., and Mehta, K. (2008) Tissue transglutaminase regulates focal adhesion kinase/AKT activation by modulating PTEN expression in pancreatic cancer cells, Clin. Cancer Res. 14, 1997.

128. Melino, G., Annicchiarico-Petruzzelli, M., Piredda, L., Candi, E., Gentile, V., Davies, P. J., and Piacentini, M. (1994) Tissue transglutaminase and apoptosis: sense and antisense transfection studies with human neuroblastoma cells, Mol. Cell Biol. 14, 6584.

129. Piacentini, M., Fesus, L., Farrace, M. G., Ghibelli, L., Piredda, L., and Melino, G. (1991) The expression of "tissue" transglutaminase in two human cancer cell lines is related with the programmed cell death (apoptosis), Eur. J. Cell Biol. 54, 246.

130. Antonyak, M. A., Miller, A. M., Jansen, J. M., Boehm, J. E., Balkman, C. E., Wakshlag, J. J., Page, R. L., and Cerione, R. A. (2004) Augmentation of tissue transglutaminase expression and activation by epidermal growth factor inhibit doxorubicin-induced apoptosis in human breast cancer cells, J. Biol. Chem. 279, 41461.

131. Datta, S., Antonyak, M. A., and Cerione, R. A. (2006) Importance of $\mathrm{Ca}(2+)$-dependent transamidation activity in the protection afforded by tissue transglutaminase against doxorubicin-induced apoptosis, Biochemistry 45, 13163.

132. Kim, D. S., Park, K. S., and Kim, S. Y. (2009) Silencing of TGase 2 sensitizes breast cancer cells to apoptosis by regulation of survival factors, Front. Biosci. 14, 2514. 
133. Park, K. S., Han, B. G., Lee, K. H., Kim, D. S., Kim, J. M., Jeon, H., Kim, H. S., Suh, S. W., Lee, E. H., Kim, S. Y., and Lee, B. I. (2009) Depletion of nucleophosmin via transglutaminase 2 cross-linking increases drug resistance in cancer cells, Cancer Lett. 274, 201.

134. El-Metwally, T. H., Hussein, M. R., Pour, P. M., Kuszynski, C. A., and Adrian, T. E. (2005) Natural retinoids inhibit proliferation and induce apoptosis in pancreatic cancer cells previously reported to be retinoid resistant, Cancer Biol. Ther. 4, 474.

135. Kweon, S. M., Lee, Z. W., Yi, S. J., Kim, Y. M., Han, J. A., Paik, S. G., and Ha, S. S. (2004) Protective role of tissue transglutaminase in the cell death induced by TNF-alpha in SH-SY5Y neuroblastoma cells, J. Biochem. Mol. Biol. 37, 185.

136. Yu, J. W. and Shi, Y. (2008) FLIP and the death effector domain family, Oncogene 27, 6216.

137. Green, D. R. (2005) Apoptotic pathways: ten minutes to dead, Cell 121, 671.

138. Scorrano, L. (2008) Caspase-8 goes cardiolipin: a new platform to provide mitochondria with microdomains of apoptotic signals? J. Cell Biol. 183, 579.

139. Chipuk, J. E. and Green, D. R. (2008) How do BCL-2 proteins induce mitochondrial outer membrane permeabilization?, Trends Cell Biol. 18, 157.

140. Scorrano, L. and Korsmeyer, S. J. (2003) Mechanisms of cytochrome c release by proapoptotic BCL-2 family members, Biochem. Biophys. Res. Commun. 304, 437.

141. Scorrano, L., Oakes, S. A., Opferman, J. T., Cheng, E. H., Sorcinelli, M. D., Pozzan, T., and Korsmeyer, S. J. (2003) BAX and BAK regulation of endoplasmic reticulum Ca2+: a control point for apoptosis, Science 300, 135.

142. Chipuk, J. E., Fisher, J. C., Dillon, C. P., Kriwacki, R. W., Kuwana, T., and Green, D. R. (2008) Mechanism of apoptosis induction by inhibition of the anti-apoptotic BCL-2 proteins, Proc. Natl. Acad. Sci. U.S.A. 105, 20327.

143. Danial, N. N. (2007) BCL-2 family proteins: critical checkpoints of apoptotic cell death, Clin Cancer Res 13, 7254.

144. Lomonosova, E. and Chinnadurai, G. (2008) BH3-only proteins in apoptosis and beyond: an overview, Oncogene 27(Suppl 1), S2.

145. Susnow, N., Zeng, L., Margineantu, D., and Hockenbery, D. M. (2009) Bcl-2 family proteins as regulators of oxidative stress, Semin. Cancer Biol. 19, 42.

146. Youle, R. J. and Strasser, A. (2008) The BCL-2 protein family: opposing activities that mediate cell death, Nat. Rev. Mol. Cell Biol. 9, 47.

147. Piacentini, M., Amendola, A., Ciccosanti, F., Falasca, L., Farrace, M. G., Mastroberardino, P. G., Nardacci, R., Oliverio, S., Piredda, L., Rodolfo, C., and Autuori, F. (2005) Type 2 transglutaminase and cell death, Prog. Exp. Tumor Res. 38, 58.

148. Piacentini, M., Autuori, F., Dini, L., Farrace, M. G., Ghibelli, L., Piredda, L., and Fesus, L. (1991) "Tissue" transglutaminase is specifically expressed in neonatal rat liver cells undergoing apoptosis upon epidermal growth factor-stimulation, Cell Tissue Res. 263, 227.

149. Piacentini, M., Ceru, M. P., Dini, L., Di Rao, M., Piredda, L., Thomazy, V., Davies, P. J., and Fesus, L. (1992) In vivo and in vitro induction of 'tissue' transglutaminase in rat hepatocytes by retinoic acid, Biochim. Biophys. Acta 1135, 171. 
150. Dhar, S. K. and St Clair, D. K. (2009) Nucleophosmin blocks mitochondrial localization of p53 and apoptosis, J. Biol. Chem. 284, 16409.

151. Battaglia, G., Farrace, M. G., Mastroberardino, P. G., Viti, I., Fimia, G. M., Van Beeumen, J., Devreese, B., Melino, G., Molinaro, G., Busceti, C. L., Biagioni, F., Nicoletti, F., and Piacentini, M. (2007) Transglutaminase 2 ablation leads to defective function of mitochondrial respiratory complex I affecting neuronal vulnerability in experimental models of extrapyramidal disorders, J. Neurochem. 100, 36.

152. Szondy, Z., Mastroberardino, P. G., Varadi, J., Farrace, M. G., Nagy, N., Bak, I., Viti, I., Wieckowski, M. R., Melino, G., Rizzuto, R., Tosaki, A., Fesus, L., and Piacentini, M. (2006) Tissue transglutaminase (TG2) protects cardiomyocytes against ischemia/reperfusion injury by regulating ATP synthesis, Cell Death Differ. 13, 1827.

153. Malorni, W., Farrace, M. G., Rodolfo, C., and Piacentini, M. (2008) Type 2 transglutaminase in neurodegenerative diseases: the mitochondrial connection, Curr. Pharm. Des. 14, 278.

154. Lesort, M., Attanavanich, K., Zhang, J., and Johnson, G. V. (1998) Distinct nuclear localization and activity of tissue transglutaminase, J. Biol. Chem. 273, 11991.

155. Robitaille, H., Proulx, R., Robitaille, K., Blouin, R., and Germain, L. (2005) The mitogen-activated protein kinase kinase kinase dual leucine zipper-bearing kinase (DLK) acts as a key regulator of keratinocyte terminal differentiation, J. Biol. Chem. 280, 12732.

156. Robitaille, K., Daviau, A., Lachance, G., Couture, J. P., and Blouin, R. (2008) Calphostin $\mathrm{C}$-induced apoptosis is mediated by a tissue transglutaminase-dependent mechanism involving the DLK/JNK signaling pathway, Cell Death Differ. 15, 1522.

157. Boosen, M., Vetterkind, S., Kubicek, J., Scheidtmann, K. H., Illenberger, S., and Preuss, U. (2009) Par-4 is an essential downstream target of DAP-like kinase (Dlk) in Dlk/Par4-mediated apoptosis, Mol. Biol. Cell 20, 4010.

158. Kogel, D., Reimertz, C., Mech, P., Poppe, M., Fruhwald, M. C., Engemann, H., Scheidtmann, K. H., and Prehn, J. H. (2001), Dlk/ZIP kinase-induced apoptosis in human medulloblastoma cells: requirement of the mitochondrial apoptosis pathway, $\mathrm{Br}$. J. Cancer 85, 1801.

159. Verderio, E. A., Telci, D., Okoye, A., Melino, G., and Griffin, M. (2003) A novel RGD-independent cell adhesion pathway mediated by fibronectin-bound tissue transglutaminase rescues cells from anoikis, J. Biol. Chem. 278, 42604.

160. Collighan, R. J. and Griffin, M. (2009) Transglutaminase 2 cross-linking of matrix proteins: biological significance and medical applications, Amino Acids 36, 659.

161. Gundemir, S. and Johnson, G. V. (2009) Intracellular localization and conformational state of transglutaminase 2: implications for cell death, PLoS One 4, e6123.

162. Antonyak, M. A., Singh, U. S., Lee, D. A., Boehm, J. E., Combs, C., Zgola, M. M., Page, R. L., and Cerione, R. A. (2001) Effects of tissue transglutaminase on retinoic acid-induced cellular differentiation and protection against apoptosis, J. Biol. Chem. $276,33582$.

163. Beck, K. E., De Girolamo, L. A., Griffin, M., and Billett, E. E. (2006) The role of tissue transglutaminase in 1-methyl-4-phenylpyridinium (MPP+)-induced toxicity in differentiated human SH-SY5Y neuroblastoma cells, Neurosci. Lett. 405, 46. 
164. Verma, A. and Mehta, K. (2007) Transglutaminase-mediated activation of nuclear transcription factor-kappaB in cancer cells: a new therapeutic opportunity, Curr. Cancer Drug Targets 7, 559.

165. Verma, A. and Mehta, K. (2007) Tissue transglutaminase-mediated chemoresistance in cancer cells, Drug Resist. Update 10, 144.

166. Boehm, J. E., Singh, U., Combs, C., Antonyak, M. A., and Cerione, R. A. (2002) Tissue transglutaminase protects against apoptosis by modifying the tumor suppressor protein p110 Rb, J. Biol. Chem. 277, 20127.

167. Antonyak, M. A., Boehm, J. E., and Cerione, R. A. (2002) Phosphoinositide 3-kinase activity is required for retinoic acid-induced expression and activation of the tissue transglutaminase, J. Biol. Chem. 277, 14712.

168. Antonyak, M. A., McNeill, C. J., Wakshlag, J. J., Boehm, J. E., and Cerione, R. A. (2003) Activation of the Ras-ERK pathway inhibits retinoic acid-induced stimulation of tissue transglutaminase expression in NIH3T3 cells, J. Biol. Chem. 278, 15859.

169. Antonyak, M. A., Jansen, J. M., Miller, A. M., Ly, T. K., Endo, M., and Cerione, R. A. (2006) Two isoforms of tissue transglutaminase mediate opposing cellular fates, Proc. Natl. Acad. Sci. U.S.A. 103, 18609.

170. Mizushima, N. and Klionsky, D. J. (2007) Protein turnover via autophagy: implications for metabolism, Annu. Rev. Nutr. 27, 19.

171. Mizushima, N. (2007) Autophagy: process and function, Genes Dev. 21, 2861.

172. Kundu, M. and Thompson, C. B. (2008) Autophagy: basic principles and relevance to disease, Annu. Rev. Pathol. 3, 427.

173. Levine, B. and Klionsky, D. J. (2004) Development by self-digestion: molecular mechanisms and biological functions of autophagy, Dev. Cell 6, 463.

174. Levine, B. and Kroemer, G. (2008) Autophagy in the pathogenesis of disease, Cell 132, 27.

175. Amano, A., Nakagawa, I., and Yoshimori, T. (2006) Autophagy in innate immunity against intracellular bacteria, J. Biochem. 140, 161.

176. Levine, B. and Deretic, V. (2007) Unveiling the roles of autophagy in innate and adaptive immunity, Nat. Rev. Immunol. 7, 767.

177. Gorski, S. M., Chittaranjan, S., Pleasance, E. D., Freeman, J. D., Anderson, C. L., Varhol, R. J., Coughlin, S. M., Zuyderduyn, S. D., Jones, S. J., and Marra, M. A. (2003) A SAGE approach to discovery of genes involved in autophagic cell death, Curr. Biol. 13, 358.

178. Hou, Y. C., Hannigan, A. M., and Gorski, S. M. (2009) An executioner caspase regulates autophagy, Autophagy 5, 530.

179. Klionsky, D. J. (2007) Autophagy: from phenomenology to molecular understanding in less than a decade, Nat. Rev. Mol. Cell Biol. 8, 931.

180. Shintani, T. and Klionsky, D. J. (2004) Cargo proteins facilitate the formation of transport vesicles in the cytoplasm to vacuole targeting pathway, J. Biol. Chem. 279, 29889.

181. Baehrecke, E. H. (2005) Autophagy: dual roles in life and death? Nat. Rev. Mol. Cell Biol. 6, 505.

182. Lum, J. J., DeBerardinis, R. J., and Thompson, C. B. (2005) Autophagy in metazoans: cell survival in the land of plenty, Nat. Rev. Mol. Cell Biol. 6, 439. 
183. Lum, J. J., Bauer, D. E., Kong, M., Harris, M. H., Li, C., Lindsten, T., and Thompson, C. B. (2005) Growth factor regulation of autophagy and cell survival in the absence of apoptosis, Cell 120, 237.

184. Levine, B. and Abrams, J. (2008) p53: The Janus of autophagy? Nat. Cell Biol. 10, 637.

185. Meijer, A. J. and Codogno, P. (2006) Signalling and autophagy regulation in health, aging and disease, Mol. Aspects Med. 27, 411.

186. Meley, D., Bauvy, C., Houben-Weerts, J. H., Dubbelhuis, P. F., Helmond, M. T., Codogno, P., and Meijer, A. J. (2006) AMP-activated protein kinase and the regulation of autophagic proteolysis, J. Biol. Chem. 281, 34870.

187. Rubinsztein, D. C., Gestwicki, J. E., Murphy, L. O., and Klionsky, D. J. (2007) Potential therapeutic applications of autophagy, Nat. Rev. Drug Discov. 6, 304.

188. Mizushima, N. and Yoshimori, T. (2007) How to interpret LC3 immunoblotting, Autophagy 3, 542 .

189. Qiao, L. and Zhang, J. (2009) Inhibition of lysosomal functions reduces proteasomal activity, Neurosci. Lett. 456, 15.

190. Turmaine, M., Raza, A., Mahal, A., Mangiarini, L., Bates, G. P., and Davies, S. W. (2000) Nonapoptotic neurodegeneration in a transgenic mouse model of Huntington's disease, Proc. Natl. Acad. Sci. U.S.A. 97, 8093.

191. Vonsattel, J. P. and DiFiglia, M. (1998) Huntington disease, J. Neuropathol. Exp. Neurol. $57,369$.

192. D'Eletto, M., Farrace, M. G., Falasca, L., Reali, V., Oliverio, S., Melino, G., Griffin, M., Fimia, G. M., and Piacentini, M. (2009) Transglutaminase 2 is involved in autophagosome maturation, Autophagy 5, 1145.

193. Kim, I., Rodriguez-Enriquez, S., and Lemasters, J. J. (2007) Selective degradation of mitochondria by mitophagy, Arch. Biochem. Biophys. 462, 245.

194. Skill, N. J., Johnson, T. S., Coutts, I. G., Saint, R. E., Fisher, M., Huang, L., El Nahas, A. M., Collighan, R. J., and Griffin, M. (2004) Inhibition of transglutaminase activity reduces extracellular matrix accumulation induced by high glucose levels in proximal tubular epithelial cells, J. Biol. Chem. 279, 47754.

195. Juprelle-Soret, M., Wattiaux-De Coninck, S., and Wattiaux, R. (1984) Presence of a transglutaminase activity in rat liver lysosomes, Eur. J. Cell Biol. 34, 271.

196. Akar, U., Ozpolat, B., Mehta, K., Fok, J., Kondo, Y., and Lopez-Berestein, G. (2007) Tissue transglutaminase inhibits autophagy in pancreatic cancer cells, Mol. Cancer Res. $5,241$.

197. Monastyrska, I., Rieter, E., Klionsky, D. J., and Reggiori, F. (2009) Multiple roles of the cytoskeleton in autophagy, Biol. Rev. Camb. Philos. Soc. 84, 431.

198. Csosz, E., Mesko, B., and Fesus, L. (2009) Transdab wiki: the interactive transglutaminase substrate database on web 2.0 surface, Amino Acids 36, 615.

199. De Laurenzi, V. and Melino, G. (2001) Gene disruption of tissue transglutaminase, Mol. Cell Biol. 21, 148.

200. Nanda, N., Iismaa, S. E., Owens, W. A., Husain, A., Mackay, F., and Graham, R. M. (2001) Targeted inactivation of Gh/tissue transglutaminase II, J. Biol. Chem. 276, 20673. 
201. Szondy, Z., Sarang, Z., Molnar, P., Nemeth, T., Piacentini, M., Mastroberardino, P. G., Falasca, L., Aeschlimann, D., Kovacs, J., Kiss, I., Szegezdi, E., Lakos, G., Rajnavolgyi, E., Birckbichler, P. J., Melino, G., and Fesus, L. (2003) Transglutaminase 2-/- mice reveal a phagocytosis-associated crosstalk between macrophages and apoptotic cells, Proc. Natl. Acad. Sci. U.S.A. 100, 7812.

202. Bernassola, F., Federici, M., Corazzari, M., Terrinoni, A., Hribal, M. L., De Laurenzi, V., Ranalli, M., Massa, O., Sesti, G., McLean, W. H., Citro, G., Barbetti, F., and Melino, G. (2002) Role of transglutaminase 2 in glucose tolerance: knockout mice studies and a putative mutation in a MODY patient, Faseb J. 16, 1371.

203. Molberg, O., McAdam, S. N., and Sollid, L. M. (2000) Role of tissue transglutaminase in celiac disease, J. Pediatr. Gastroenterol. Nutr. 30, 232.

204. Hoffner, G. and Djian, P. (2005) Transglutaminase and diseases of the central nervous system, Front. Biosci. 10, 3078.

205. Issa, R., Zhou, X., Constandinou, C. M., Fallowfield, J., Millward-Sadler, H., Gaca, M. D., Sands, E., Suliman, I., Trim, N., Knorr, A., Arthur, M. J., Benyon, R. C., and Iredale, J. P. (2004) Spontaneous recovery from micronodular cirrhosis: evidence for incomplete resolution associated with matrix cross-linking, Gastroenterology 126, 1795.

206. Mirza, A., Liu, S. L., Frizell, E., Zhu, J., Maddukuri, S., Martinez, J., Davies, P., Schwarting, R., Norton, P., and Zern, M. A. (1997) A role for tissue transglutaminase in hepatic injury and fibrogenesis, and its regulation by NF-kappaB, Am. J. Physiol. $272, \mathrm{G} 281$.

207. Johnson, T. S., El-Koraie, A. F., Skill, N. J., Baddour, N. M., El Nahas, A. M., Njloma, M., Adam, A. G., and Griffin, M. (2003) Tissue transglutaminase and the progression of human renal scarring, J. Am. Soc. Nephrol. 14, 2052.

208. Mangala, L. S., Fok, J. Y., Zorrilla-Calancha, I. R., Verma, A., and Mehta, K. (2007) Tissue transglutaminase expression promotes cell attachment, invasion and survival in breast cancer cells, Oncogene 26, 2459.

209. Facchiano, F., Facchiano, A., and Facchiano, A. M. (2006) The role of transglutaminase2 and its substrates in human diseases, Front. Biosci. 11, 1758.

210. Eguchi, K. (2001) Apoptosis in autoimmune diseases, Intern. Med. 40, 275.

211. Navratil, J. S., Sabatine, J. M., and Ahearn, J. M. (2004) Apoptosis and immune responses to self, Rheum. Dis. Clin. North Am. 30, 193.

212. Savill, J., Dransfield, I., Gregory, C., and Haslett, C. (2002) A blast from the past: clearance of apoptotic cells regulates immune responses, Nat. Rev. Immunol. 2, 965.

213. Falasca, L., Iadevaia, V., Ciccosanti, F., Melino, G., Serafino, A., and Piacentini, M. (2005) Transglutaminase type II is a key element in the regulation of the antiinflammatory response elicited by apoptotic cell engulfment, J. Immunol. 174, 7330.

214. Neininger, A., Kontoyiannis, D., Kotlyarov, A., Winzen, R., Eckert, R., Volk, H. D., Holtmann, H., Kollias, G., and Gaestel, M. (2002) MK2 targets AU-rich elements and regulates biosynthesis of tumor necrosis factor and interleukin-6 independently at different post-transcriptional levels, J. Biol. Chem. 277, 3065.

215. Suzuki, K., Hino, M., Kutsuna, H., Hato, F., Sakamoto, C., Takahashi, T., Tatsumi, N., and Kitagawa, S. (2001) Selective activation of p38 mitogen-activated protein kinase cascade in human neutrophils stimulated by IL-1beta, J. Immunol. 167, 5940. 
216. Lee, J. C. and Young, P. R. (1996) Role of CSB/p38/RK stress response kinase in LPS and cytokine signaling mechanisms, J. Leukoc. Biol. 59, 152.

217. Alleva, D. G., Johnson, E. B., Wilson, J., Beller, D. I., and Conlon, P. J. (2001) SJL and NOD macrophages are uniquely characterized by genetically programmed, elevated expression of the IL-12(p40) gene, suggesting a conserved pathway for the induction of organ-specific autoimmunity, J. Leukoc. Biol. 69, 440.

218. Alleva, D. G., Pavlovich, R. P., Grant, C., Kaser, S. B., and Beller, D. I. (2000) Aberrant macrophage cytokine production is a conserved feature among autoimmune-prone mouse strains: elevated interleukin (IL)-12 and an imbalance in tumor necrosis factoralpha and IL-10 define a unique cytokine profile in macrophages from young nonobese diabetic mice, Diabetes 49, 1106.

219. Liu, J. and Beller, D. (2002) Aberrant production of IL-12 by macrophages from several autoimmune-prone mouse strains is characterized by intrinsic and unique patterns of NF-kappa B expression and binding to the IL-12 p40 promoter, J. Immunol. 169, 581.

220. Qu, X., Zou, Z., Sun, Q., Luby-Phelps, K., Cheng, P., Hogan, R. N., Gilpin, C., and Levine, B. (2007) Autophagy gene-dependent clearance of apoptotic cells during embryonic development, Cell 128, 931.

221. Lolis, E. and Bucala, R. (2003) Therapeutic approaches to innate immunity: severe sepsis and septic shock, Nat. Rev. Drug Discov. 2, 635.

222. Perl, M., Chung, C. S., Garber, M., Huang, X., and Ayala, A. (2006) Contribution of antiinflammatory/immune suppressive processes to the pathology of sepsis, Front. Biosci. $11,272$.

223. Bantel, H. and Schulze-Osthoff, K. (2009) Cell death in sepsis: a matter of how, when, and where, Crit. Care 13, 173.

224. Perl, M., Chung, C. S., Swan, R., and Ayala, A. (2007) Role of Programmed Cell Death in the Immunopathogenesis of Sepsis, Drug Discov. Today Dis. Mech. 4, 223.

225. Bowness, J. M. and Tarr, A. H. (1997) Increase in transglutaminase and its extracellular products in response to an inflammatory stimulus by lipopolysaccharide, Mol. Cell Biochem. 169, 157.

226. Leu, R. W., Herriott, M. J., Moore, P. E., Orr, G. R., and Birckbichler, P. J. (1982) Enhanced transglutaminase activity associated with macrophage activation. Possible role in Fc-mediated phagocytosis, Exp. Cell Res. 141, 191.

227. Park, K. C., Chung, K. C., Kim, Y. S., Lee, J., Joh, T. H., and Kim, S. Y. (2004) Transglutaminase 2 induces nitric oxide synthesis in BV-2 microglia, Biochem. Biophys. Res. Commun. 323, 1055.

228. Falasca, L., Farrace, M. G., Rinaldi, A., Tuosto, L., Melino, G., and Piacentini, M. (2008) Transglutaminase type II is involved in the pathogenesis of endotoxic shock, J. Immunol. $180,2616$.

229. Liu, S. F. and Malik, A. B. (2006) NF-kappa B activation as a pathological mechanism of septic shock and inflammation, Am. J. Physiol. Lung Cell Mol. Physiol. 290, L622.

230. Baeuerle, P. A. and Baltimore, D. (1988) I kappa B: a specific inhibitor of the NF-kappa B transcription factor, Science 242, 540. 
231. Lee, J., Kim, Y. S., Choi, D. H., Bang, M. S., Han, T. R., Joh, T. H., and Kim, S. Y. (2004) Transglutaminase 2 induces nuclear factor-kappaB activation via a novel pathway in BV-2 microglia, J. Biol. Chem. 279, 53725.

232. Hasosah, M., Davidson, G., and Jacobson, K. (2009) Persistent elevated tissuetransglutaminase in cystic fibrosis, J. Paediatr. Child Health 45, 172.

233. Maiuri, L., Luciani, A., Giardino, I., Raia, V., Villella, V. R., D’Apolito, M., PettoelloMantovani, M., Guido, S., Ciacci, C., Cimmino, M., Cexus, O. N., Londei, M., and Quaratino, S. (2008) Tissue transglutaminase activation modulates inflammation in cystic fibrosis via PPARgamma down-regulation, J. Immunol. 180, 7697.

234. Luciani, A., Villella, V. R., Vasaturo, A., Giardino, I., Raia, V., Pettoello-Mantovani, M., D’Apolito, M., Guido, S., Leal, T., Quaratino, S., and Maiuri, L. (2009) SUMOylation of tissue transglutaminase as link between oxidative stress and inflammation, J. Immunol. $183,2775$.

235. Johnson, W. G. (2000) Late-onset neurodegenerative diseases-the role of protein insolubility, J. Anat. 196(Pt 4), 609.

236. Kang, J., Lemaire, H. G., Unterbeck, A., Salbaum, J. M., Masters, C. L., Grzeschik, K. H., Multhaup, G., Beyreuther, K., and Muller-Hill, B. (1987) The precursor of Alzheimer's disease amyloid A4 protein resembles a cell-surface receptor, Nature 325, 733.

237. Masters, C. L., Multhaup, G., Simms, G., Pottgiesser, J., Martins, R. N., and Beyreuther, K. (1985) Neuronal origin of a cerebral amyloid: neurofibrillary tangles of Alzheimer's disease contain the same protein as the amyloid of plaque cores and blood vessels, Embo J. 4, 2757.

238. Masters, C. L., Simms, G., Weinman, N. A., Multhaup, G., McDonald, B. L., and Beyreuther, K. (1985) Amyloid plaque core protein in Alzheimer disease and Down syndrome, Proc. Natl. Acad. Sci. U.S.A. 82, 4245.

239. Delacourte, A. and Defossez, A. (1986) Alzheimer's disease: Tau proteins, the promoting factors of microtubule assembly, are major components of paired helical filaments, $J$. Neurol. Sci. 76, 173.

240. Kosik, K. S., Joachim, C. L., and Selkoe, D. J. (1986) Microtubule-associated protein tau (tau) is a major antigenic component of paired helical filaments in Alzheimer disease, Proc. Natl. Acad. Sci. U.S.A. 83, 4044.

241. Biernat, J., et al. (1992) The switch of tau protein to an Alzheimer-like state includes the phosphorylation of two serine-proline motifs upstream of the microtubule binding region, Embo J. 11, 1593.

242. Crowther, R. A., Olesen, O. F., Jakes, R., and Goedert, M. (1992) The microtubule binding repeats of tau protein assemble into filaments like those found in Alzheimer's disease, FEBS Lett. 309, 199.

243. Goedert, M., Spillantini, M. G., Cairns, N. J., and Crowther, R. A. (1992) Tau proteins of Alzheimer paired helical filaments: abnormal phosphorylation of all six brain isoforms, Neuron 8, 159.

244. Appelt, D. M., Kopen, G. C., Boyne, L. J., and Balin, B. J. (1996) Localization of transglutaminase in hippocampal neurons: implications for Alzheimer's disease, J. Histochem. Cytochem. 44, 1421. 
245. Miller, C. C. and Anderton, B. H. (1986) Transglutaminase and the neuronal cytoskeleton in Alzheimer's disease, J. Neurochem. 46, 1912.

246. Appelt, D. M. and Balin, B. J. (1997) The association of tissue transglutaminase with human recombinant tau results in the formation of insoluble filamentous structures, Brain Res. 745, 21.

247. Miller, M. L. and Johnson, G. V. (1995) Transglutaminase cross-linking of the tau protein, J. Neurochem. 65, 1760.

248. Gusella, J. F. and MacDonald, M. E. (1993) Hunting for Huntington's disease, Mol. Genet. Med. 3, 139.

249. Andrew, S. E., et al. (1993) The relationship between trinucleotide (CAG) repeat length and clinical features of Huntington's disease, Nat. Genet. 4, 398.

250. Davies, S. W., Turmaine, M., Cozens, B. A., DiFiglia, M., Sharp, A. H., Ross, C. A., Scherzinger, E., Wanker, E. E., Mangiarini, L., and Bates, G. P. (1997) Formation of neuronal intranuclear inclusions underlies the neurological dysfunction in mice transgenic for the HD mutation, Cell 90, 537.

251. DiFiglia, M., Sapp, E., Chase, K. O., Davies, S. W., Bates, G. P., Vonsattel, J. P., and Aronin, N. (1997) Aggregation of huntingtin in neuronal intranuclear inclusions and dystrophic neurites in brain, Science 277, 1990.

252. Saudou, F., Finkbeiner, S., Devys, D., and Greenberg, M. E. (1998) Huntingtin acts in the nucleus to induce apoptosis but death does not correlate with the formation of intranuclear inclusions, Cell 95, 55.

253. Gentile, V., Sepe, C., Calvani, M., Melone, M. A., Cotrufo, R., Cooper, A. J., Blass, J. P., and Peluso, G. (1998) Tissue transglutaminase-catalyzed formation of high-molecularweight aggregates in vitro is favored with long polyglutamine domains: a possible mechanism contributing to CAG-triplet diseases, Arch. Biochem. Biophys. 352, 314.

254. Lesort, M., Tucholski, J., Miller, M. L., and Johnson, G. V. (2000) Tissue transglutaminase: a possible role in neurodegenerative diseases, Prog. Neurobiol. 61, 439.

255. Lesort, M., Tucholski, J., Zhang, J., and Johnson, G. V. (2000) Impaired mitochondrial function results in increased tissue transglutaminase activity in situ, J. Neurochem. 75 , 1951.

256. Winslow, A. R. and Rubinsztein, D. C. (2008) Autophagy in neurodegeneration and development, Biochim. Biophys. Acta 1782, 723.

257. Williams, A., Jahreiss, L., Sarkar, S., Saiki, S., Menzies, F. M., Ravikumar, B., and Rubinsztein, D. C. (2006) Aggregate-prone proteins are cleared from the cytosol by autophagy: therapeutic implications, Curr. Top. Dev. Biol. 76, 89.

258. Yue, Z., Horton, A., Bravin, M., DeJager, P. L., Selimi, F., and Heintz, N. (2002) A novel protein complex linking the delta 2 glutamate receptor and autophagy: implications for neurodegeneration in lurcher mice, Neuron 35, 921.

259. Martinez-Vicente, M. and Cuervo, A. M. (2007) Autophagy and neurodegeneration: when the cleaning crew goes on strike, Lancet Neurol 6, 352.

260. Strnad, P., Harada, M., Siegel, M., Terkeltaub, R. A., Graham, R. M., Khosla, C., and Omary, M. B. (2007) Transglutaminase 2 regulates mallory body inclusion formation and injury-associated liver enlargement, Gastroenterology 132, 1515. 
261. Fujitani, Y., Kawamori, R., and Watada, H. (2009) The role of autophagy in pancreatic beta-cell and diabetes, Autophagy 5, 280.

262. Jung, H. S., Chung, K. W., Won Kim, J., Kim, J., Komatsu, M., Tanaka, K., Nguyen, Y. H., Kang, T. M., Yoon, K. H., Kim, J. W., Jeong, Y. T., Han, M. S., Lee, M. K., Kim, K. W., Shin, J., and Lee, M. S. (2008) Loss of autophagy diminishes pancreatic beta cell mass and function with resultant hyperglycemia, Cell Metab. 8, 318.

263. Gottlieb, R. A. and Mentzer, R. M. (2010) Autophagy during cardiac stress: joys and frustrations of autophagy, Annu. Rev. Physiol. 72, 45.

264. Gustafsson, A. B. and Gottlieb, R. A. (2009) Autophagy in ischemic heart disease, Circ. Res. $104,150$.

265. Rothermel, B. A. and Hill, J. A. (2008) Autophagy in load-induced heart disease, Circ. Res. 103, 1363.

266. Wang, Z. V., Rothermel, B. A., and Hill, J. A. (2010), Autophagy in hypertensive heart disease, J. Biol. Chem. 285, 8509.

267. Terman, A. and Brunk, U. T. (2005) The aging myocardium: roles of mitochondrial damage and lysosomal degradation, Heart Lung Circ. 14, 107.

268. Terman, A. and Brunk, U. T. (2005) Autophagy in cardiac myocyte homeostasis, aging, and pathology, Cardiovasc. Res. 68, 355.

269. Nakai, A., Yamaguchi, O., Takeda, T., Higuchi, Y., Hikoso, S., Taniike, M., Omiya, S., Mizote, I., Matsumura, Y., Asahi, M., Nishida, K., Hori, M., Mizushima, N., and Otsu, K. (2007) The role of autophagy in cardiomyocytes in the basal state and in response to hemodynamic stress, Nat. Med. 13, 619.

270. Tannous, P., Zhu, H., Nemchenko, A., Berry, J. M., Johnstone, J. L., Shelton, J. M., Miller, F. J., Jr., Rothermel, B. A., and Hill, J. A. (2008) Intracellular protein aggregation is a proximal trigger of cardiomyocyte autophagy, Circulation 117, 3070.

271. Porrello, E. R., D’Amore, A., Curl, C. L., Allen, A. M., Harrap, S. B., Thomas, W. G., and Delbridge, L. M. (2009) Angiotensin II type 2 receptor antagonizes angiotensin II type 1 receptor-mediated cardiomyocyte autophagy, Hypertension 53, 1032.

272. Porrello, E. R. and Delbridge, L. M. (2009) Cardiomyocyte autophagy is regulated by angiotensin II type 1 and type 2 receptors, Autophagy 5, 1215.

273. AbdAlla, S., Lother, H., Langer, A., el Faramawy, Y., and Quitterer, U. (2004) Factor XIIIA transglutaminase crosslinks AT1 receptor dimers of monocytes at the onset of atherosclerosis, Cell 119, 343.

274. Sane, D. C., Kontos, J. L., and Greenberg, C. S. (2007) Roles of transglutaminases in cardiac and vascular diseases, Front. Biosci. 12, 2530. 